



The National Bureau of Standards ${ }^{1}$ was established by an act of Congress March 3 , 1901. The Bureau's overall goal is to strengthen and advance the Nation's science and technology and facilitate their effective application for public benefit. To this end, the Bureau conducts research and provides: (1) a basis for the Nation's physical measurement system, (2) scientific and technological services for industry and government, (3) a technical basis for equity in trade, and (4) technical services to promote public safety. The Bureau consists of the Institute for Basic Standards, the Institute for Materials Research, the Institute for Applied Technology, the Center for Computer Sciences and Technology, and the Office for Information Programs.

THE INSTITUTE FOR BASIC STANDARDS provides the central basis within the United States of a complete and consistent system of physical measurement; coordinates that system with measurement systems of other nations; and furnishes essential services leading to accurate and uniform physical measurements throughout the Nation's scientific community, industry, and commerce. The Institute consists of a Center for Radiation Research, an Office of Measurement Services and the following divisions:

Applied Mathematics-Electricity-Heat-Mechanics-Optical Physics-Linac Radiation ${ }^{2}$ - Nuclear Radiation ${ }^{2}$ - Applied Radiation ${ }^{2}$ - Quantum Electronics ${ }^{3}$ Electromagnetics ${ }^{3}$ - Time and Frequency ${ }^{3}$-Laboratory Astrophysics ${ }^{3}$ - Cryogenics ${ }^{3}$.

THE INSTITUTE FOR MATERIALS RESEARCH conducts materials research leading to improved methods of measurement, standards, and data on the properties of well-characterized materials needed by industry, commerce, educational institutions, and Government; provides advisory and research services to other Government agencies; and develops, produces, and distributes standard reference materials. The Institute consists of the Office of Standard Reference Materials and the following divisions:

Analytical Chemistry-Polymers-Metallurgy-Inorganic Materials-Reactor Radiation-Physical Chemistry.

THE INSTITUTE FOR APPLIED TECHNOLOGY provides technical services to promote the use of available technology and to facilitate technological innovation in industry and Government; cooperates with public and private organizations leading to the development of technological standards (including mandatory safety standards), codes and methods of test; and provides technical advice and services to Government agencies upon request. The Institute also monitors NBS engineering standards activities and provides liaison between NBS and national and international engineering standards bodies. The Institute consists of the following technical divisions and offices:

Engineering Standards Services-Weights and Measures-Flammable FabricsInvention and Innovation-Vehicle Systems Research-Product Evaluation Technology-Building Research-Electronic Technology-Technical AnalysisMeasurement Engineering.

THE CENTER FOR COMPUTER SCIENCES AND TECHNOLOGY conducts research and provides technical services designed to aid Government agencies in improving cost effectiveness in the conduct of their programs through the selection, acquisition, and effective utilization of automatic data processing equipment; and serves as the principal focus within the executive branch for the development of Federal standards for automatic data processing equipment, techniques, and computer languages. The Center consists of the following offices and divisions:

Information Processing Standards-Computer Information-Computer Services -Systems Development-Information Processing Technology.

THE OFFICE FOR INFORMATION PROGRAMS promotes optimum dissemination and accessibility of scientific information generated within NBS and other agencies of the Federal Government; promotes the development of the National Standard Reference Data System and a system of information analysis centers dealing with the broader aspects of the National Measurement System; provides appropriate services to ensure that the NBS staff has optimum accessibility to the scientific information of the world, and directs the public information activities of the Bureau. The Office consists of the following organizational units:

Office of Standard Reference Data-Office of Technical Information and Publications-Library-Office of Public Information-Office of International Relations. 1 Headquarters and Laboratories at Gaithersburg, Maryland, unless otherwise noted; mailing address Washing-

2 Part of the Center for Radiation Research.

${ }^{3}$ Located at Boulder, Colorado 80302. 


\title{
BOLOVAC Systems for Measuring Electrical Quantities From 0.5 MHz Through Microwaves t. Monograph no.123
}

\author{
Myron C. Selby
}

Electromagnetics Division Institute for Basic Standards National Bureau of Standards Boulder, Colorado 80302

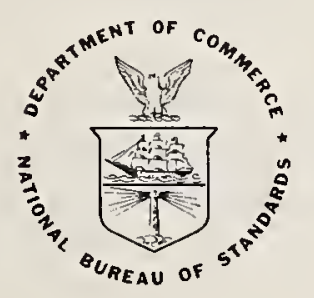

US National Bureau of Standards Monograph 123 , 1,

Nat. Bur. Stand. (U.S.) Monogr. 123, 24 pages (Jan. 1972) CODEN: NBSMA

Issued January 1972 
Library of Congress Catalog Card Number: 79-183998 


\section{Contents}

1. Introduction

2. Principle of Operation

3. Bolovac Applications

3.1. The Bolovac as a Source of Known Voltage

3.2. The Bolovac for Measuring Power

a. Power Measurement with Bolovac Operating in the Voltage Mode

(1) Evaluation of Source of RF Power

(2) Power-meter Calibration

b. Power Measurement Using the Bolovac as a Power Absorbing Mount (Power-absorption Mode) _-_----

(1) Bolovac as Absorption Mount to Evaluate Quality of RF.Power Source --------------------------

(2) The Bolovac as an Absorption Mount to Calibrate Power Meters --

(3) Calibration of Low-level Signal Generators Using the Bolovac in the Power-absorption Mode --------

3.3. The Bolovac as a RF-current Standard

3.4. Application of the Bolovac for Insertion-loss Measurements

3.5. Self-evaluation of the Bolovac

3.6. Other Bolovac Applications

4. Structural Features of the Bolovac

4.1. Mechanical Design

4.2. Thin-film Materials for the Bolovac

5. Auxiliary Equipment

6. Conclusion and Future Prospects

7. References

8. Appendix

\section{List of Figures}

1. Basic components of the Bolovac

(a) Middle plate of the Bolovac supports the bolometer and the center conductor

(b) Equivalent circuit of the bolometer film and its substrate and of the center-conductor supporting bead

2. Schematic diagram illustrating principle of standardizing $R F$ voltmeter in terms of known voltage generated by $R_{m}$ located in a transverse plane, $\mathrm{A}$, of a TEM mode

3. Schematic diagrams showing the applications of the Bolovac for
(a) Voltage standardization and
(b) Current standardization

4. Measurement of voltage amplitude bandwidth of oscilloscope with a Bolovac -

5. Graphical determination of $V_{B}$

6. Symbol designations unless otherwise labeled

7. Measurement of $P_{c}, P_{o}$, and $P_{n}$ with the Bolovac used as a voltmeter. (See a simpler method for $P_{c}$ and $P_{o}$ with the BOLOVAC operated in the power-absorption mode.)

8. Calibration of power meter in two steps with Bolovac operating in the voltage mode

9. Calibration of power meter in one step with Bolovac operating in the voltage mode -

10. Application of the Bolovac as an absorption type power mount. The sliding short may be replaced by a shielding tube or may be eliminated, depending on the frequency and requirements. Note that the thin film is now facing the source.

11. Measurement of maximum available power from a source with the Bolovac as an absorption power mount -------

12. Measurement of $P_{o}$ with Bolovac as an absorption mount

13. Carrier output calibration of low-level signal generators employing Bolovac in the power-absorption mode of operation 


\section{List of Figures-Continued}

14. Self checking of Bolovac

15. Exploded view of core for voltage standardization

16. Current core exploded

17. Bolometric film on two-mil plastic substrate

18. Core (with voltage plate) and auxiliary capacitor of Bolovac ---

19. Voltage core and auxiliary capacitor

20. Interchangeable bolometer cell (employing a 2-mil substrate) mounted in the center plate of the Bolovac

21. Bolovac set up to calibrate attenuator-thermoelement voltmeter (ATVM) 


\title{
BOLOVAC Systems for Measuring Electrical Quantities From 0.5 MHz Through Microwaves
}

\author{
Myron C. Selby*
}

\begin{abstract}
A novel device-the BOLOVAC-is employed in measurement systems that furnish known voltages and currents up to $18 \mathrm{GHz}$, remove serious difficulties in power measurements, and are applicable in impedance, attenuation and other measurements. Typical of such measurements are the evaluation of rf power sources; calibration of power meters; measurement of net and incident power flow in a system; calibration of signal generators, voltmeters, current meters, picosecond-rise-time pulse-display oscilloscopes, spectrum analyzers; determination of insertion loss of components; and calibration of directional couplers. The Bolovac also serves as an accurately known resistive termination for match or mismatch applications from LF through microwaves.
\end{abstract}

Key words: BOLOVAC; calibration of current meters through microwaves; calibration of power meters through microwaves; calibration of voltmeters through microwaves; current measurement; disk-type bolometer evaluation; frequency-domain pulse evaluation; measurement of microwave current; measurement of microwave power; measurement of microwave voltage; mismatch error; picosecond rise-time pulse evaluation; power measurement; pulse-rise time standardization; sampling oscilloscope standardization; spectrum analyzer standardization; termination mismatch error elimination; thin-film bolometers; voltage measurement.

\section{Introduction}

BOLOVAC is an acronym of "BOLOmetric Voltage and Current," a novel device for measuring electrical quantities up through microwave frequencies. Generally connected in series with a coaxial system, it measures voltage, current or power. Its upper frequency range is limited to $9 \mathrm{GHz}$ in a $14-\mathrm{mm}$ system or to $18 \mathrm{GHz}$ in a $7-\mathrm{mm}$ system and to higher frequencies in smaller diameter systems. At the National Bureau of Standards (NBS) so far, its application only with 7-mm systems has been evaluated. The Bolovac offers the first means of furnishing or measuring microwave voltages directly and calibrating indicators of microwave currents.

The relatively simple construction of the Bolovac consists of a coaxial assembly of three washer-type disks (fig. 1) that form the outer conductor and a common center conductor $[1] .{ }^{1}$ One disk sandwiched between the other two, carries a bolometric sensing element connected across the output of the coaxial mount between the disk and the center conductor. The sensor consists of a thin-film resistor having a relatively high temperature coefficient of resistivity. A 0.001- to 0.002 -in (one- to two-mil) ${ }^{2}$ thick dielectric film insulates the outside disks from the center disk to form rf-blocking capacitors.

The dynamic range of the Bolovac depends on the resistance and other characteristics of the bolometerelement (bolometer) and on the accuracies desired;

* Electromagnetics Division, National Bureau of Standards, Boulder, Colo. 80302

${ }^{1}$ Figures in brackets indicate the literature references at the end of this paper.

${ }^{2}$ One inch is equal to 2.54 centimeters. it is typically $100 \mathrm{mV}$ to $2 \mathrm{~V}$ ( $10 \mathrm{~mA}$ to $200 \mathrm{~mA}$ ) for a $10-\Omega$ bolometer and accuracies of the order of one percent. This voltage range corresponds to 200 $\mu \mathrm{W}$ to $80 \mathrm{~mW}$ in a $50-\Omega$ system. Although one-ohm to $50-\Omega$ and higher resistance bolometers can be used, the National Bureau of Standards, so far, has only fabricated a few units above $10 \Omega$. Voltage, current and power levels depend on the bolometric element resistance, but the relative dynamic range of each

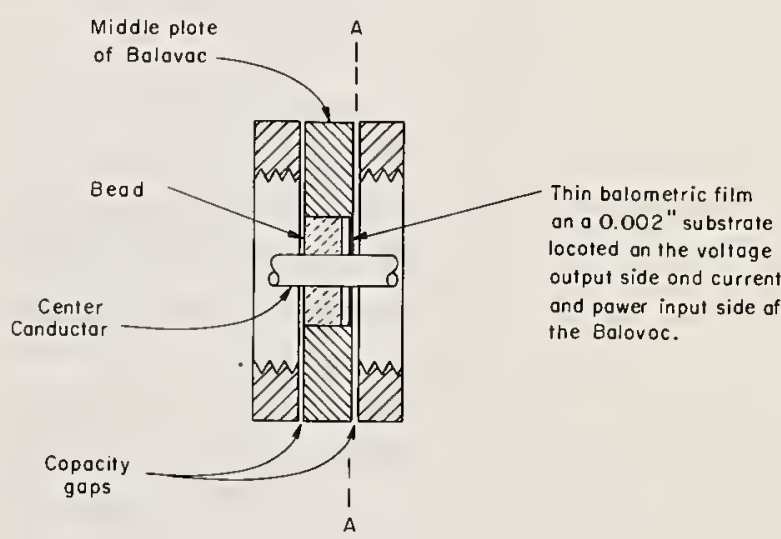

(a)
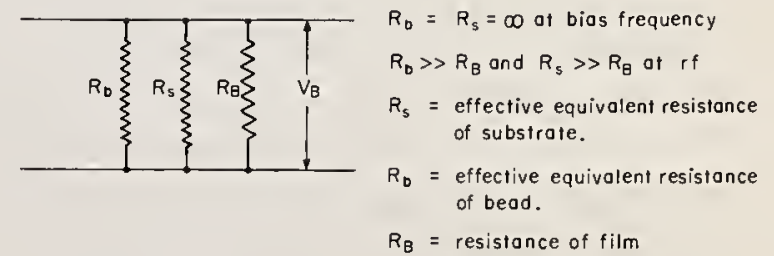

(b)

Figure 1. Basic components of the Bolovac.

(a) Middle plate of the Bolovac supports the bolometer and the center conductor.

(b) Equivalent circuit of the bolometer film and its substrate and of the center-conductor supporting bead. 
element remains about the same.

Accurate high-frequency and microwave voltages and currents are important to the following needs: [2]

-Calibrating voltmeters, signal generators, fieldstrength meters, voltage spectrum analyzers, thermoelements, etc.

-Measuring frequency response, i.e., fidelity of oscilloscopes displaying modern narrow pulses having rise-times of several picoseconds $\left(10^{-12}\right.$ second). To date the $\mathrm{CW}$ frequency response is the only practical means of standardizing pulsedisplay instruments and now the Bolovac provides a unique tool for this purpose at the presently required frequencies.

-Measuring voltage and current transfer characteristics of solid state, integrated, monolithic and epitaxial components and circuits.

-Measuring voltage-breakdown characteristics of ordinary-and miniature-diameter transmission lines, including strip lines.

-Measuring fields (and their polarization) as detected by probes and antennas in enclosed or open spaces.

-Measuring microwave characteristics of very thin conductive, semiconductive and superconductive films, and in other $\mathrm{R} \& \mathrm{D}$ work.

-In general for all purposes for which measurement of dc voltages and currents are made.

The Bolovac is particularly attractive for power measurement for the following reasons briefly stated:

-It eliminates the need to measure source and load reflection coefficients. Traditional methods necessitate measuring the magnitude and phase of these coefficients required to compute power flow from complex equations. Failure to measure these coefficients can result in uncertainties of 25 percent or more called "termination mismatch errors". Seldom are these measurements and computations done even in the best of laboratories.

-It eliminates the need for charts giving limits of mismatch errors. Such charts, can be used to reduce the above uncertainties, provided that the reflection-coefficient magnitudes are measured. Again, limits on the uncertainties may be 15 percent or higher. The Bolovac, on the other hand, permits measuring definite values of power under any practicable matching conditions.

- It eliminates the need to calibrate power meters for "effective efficiency" or "calibration factors". With the Bolovac rf power is measured directly in terms of dc or audio power without any corrections for most present day practical needs.
-It eliminates the need to calibrate power meters at $\mathrm{dc}$ or audio frequencies as nearly always required. The Bolovac serves as a power-absorption mount or furnishes known rf voltages to calibrate other power meters.

-The Bolovac's frequency range extends down to $100 \mathrm{kHz}$ or lower as compared to $10 \mathrm{MHz}$ for most conventional meters. It can also measure considerably higher power levels than those indicated.

Other advantages introduced by the Bolovac were mentioned in previous papers $[3,4]$ and are pointed out here.

The Bolovac, when terminated in a sliding short, serves as an accurately known adjustable termination (for impedance, attenuation or power measurement) over its entire frequency range. It can be used to measure insertion loss (attenuation) of components and networks, and to calibrate directional couplers or to take the place of such couplers as power-transmission monitors. With proper adapters it can be used to measure power in any uniconductor waveguides operating in any mode. It may even be applied for self-evaluation because there are two ways (modes) of operation of the Bolovac for power measurementthe voltage mode and the power-absorption mode; checking one against the other will expose irregularly high internal losses or other defects within the Bolovac itself.

The most attractive and practical features of the Bolovac are (1) the relative simplicity of the principles of its operation and application, reducing the concepts practically to those at $\mathrm{dc}$, and (2) the use of the Bolovac could eliminate ruinous inflation of the uncertainty that results from the present need of calibrating power and other meters in a succession of laboratories. These laboratories pass on rf-reference standards from high echelons or lower. The Bolovac needs no rf calibration and can be used in any laboratory having de standards that are good enough for immediate needs.

This paper describes in some detail how the Bolovac works, what its structural components are, what are the methods and steps of procedure in its various major applications, and reasons for its advantages. The emphasis is on applications. Present status at the National Bureau of Standards relating to fabricating the most important component of the Bolovac-the bolometric disk-is briefly pointed out.

Considerable latitude for further innovation, improvement and refinement is available to manufacturers expressing interest in marketing the Bolovac. 


\section{Principle of Operation}

Because comprehensive analyses of the Bolovac were presented in previous papers $[3,4,5]$, a brief discussion of the basic elements and derived equations, should suffice for its practical applications.

A thin metallic-film placed in a plane A, (fig. 2), perpendicular to the axis of a coaxial line, has an rf resistance theoretically shown [5] to be equal to its $\mathrm{dc}$ resistance to better than 0.015 percent at all frequencies up to $36 \mathrm{GHz}$. This is true provided (1) the thickness of the film is 7 percent or less than the penetration of the current into the corresponding solid metal at $40 \mathrm{GHz}$ and (2) the electric-field lines in the coaxial line are perpendicular to its axis. The latter condition holds in the vast majority of normally operated systems. As the current penetration increases at frequencies below $36 \mathrm{GHz}$, the film thickness is a smaller fraction of penetration and the rf-to-dc equivalence becomes closer as the frequency decreases.

Imagine two coaxial lines joined by connectors in plane A-A (fig. 2). The ends of the lines connect to an $\mathrm{rf}$ power source and a load, respectively. The load, a voltage indicating instrument, and the coaxial line form a voltmeter that measures the voltage in plane A. Opening the connectors, inserting a thinfilm disk in plane $\mathrm{A}$ and reconnecting the lines, results in an $\mathrm{rf}$ voltage across the film disk and $\mathrm{rf}$ power dissipated in it. The power is given by:

$$
P_{B r f}=V_{B}^{2} / R_{B r f}=V_{B}^{2} / R_{B d c}
$$

where:

$\mathrm{V}_{\mathrm{B}}=\mathrm{rf}$ voltage across the film disk,

$\mathrm{R}_{\mathrm{Brf}}=\mathrm{rf}$ resistance of the disk,

$\mathrm{R}_{\mathrm{Bdc}}=\mathrm{dc}$ resistance of the disk.

The rf power dissipated in the film can be measured to find $V_{B}$ by the so-called "power substitution" method as follows. For maximum sensitivity, this film should have as high as possible a temperature coeffi-

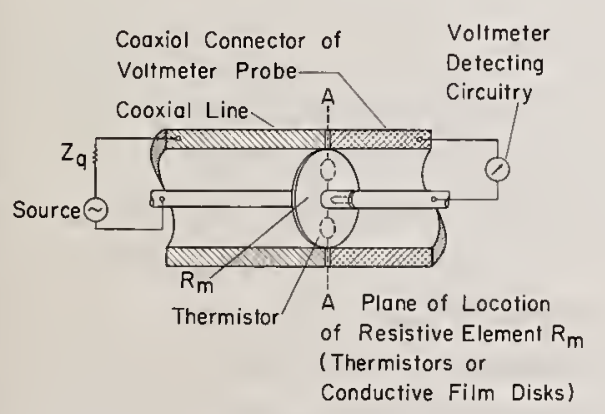

FiguRE 2. Schematic diagram illustrating principle of standardizing $R F$ voltmeter in terms of known voltage generated by $R_{\mathrm{m}}$ located in a transverse plane, $A$, of a TEM mode. cient of resistivity. Physically splitting the disk in two along a diameter (not shown) perpendicular to line A-A enables the two halves to be connected in series for dc and in parallel for rf. We feed dc or audio power (called "bias power") to the film. For simplicity we will refer to the thin film disk and its supporting substrate material as the "bolometer". The bias is isolated from the rf power by blocking capacitors, $C_{b}$, built into the assembly (fig. 3 ). The value of $C_{b}$ and its construction is such that the rf-voltage drop across it is always negligible.

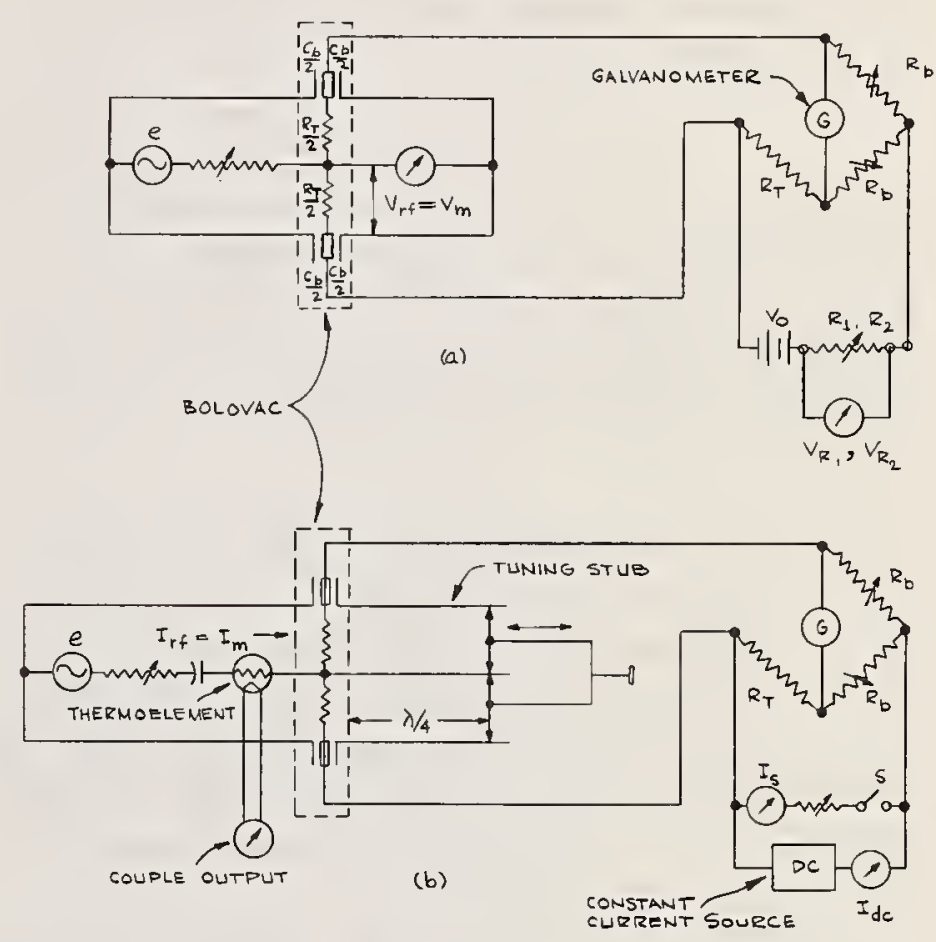

Figure 3. Schematic diagrams showing the applications of the Bolovac for

(a) Voltage standardization and

(b) Current standardization.

With the rf source turned off, a certain amount of bias power, $P_{B O}$, fixes the bolometer resistance at a desired value of $R_{B d c}$. So far National Bureau of Standards uses dc to bias the bolometers. Turning on the rf source causes the bolometer resistance to change up or down and some bias power must be removed from the bolometer to restore its original resistance $R_{B r f}=R_{B d c}$. The dc bridges (fig. 3) indicate when this resistance is restored. A measurement of the substituted bias power is given by:

$$
\boldsymbol{P}_{B r f}=\boldsymbol{P}_{B 0}-\boldsymbol{P}_{B 1}
$$

where: $P_{B 1}=$ bias power measured after the $\mathrm{rf}$ is turned on. The bridges also indicate what $R_{B d c}$ is, provided that we incorporate an important structural detail of the Bolovac. Bolometers comprising the film disks and their mounts are split in half along one 
diameter. Half the bolometer resistance is $\frac{1}{2} R_{T}$; the bridge measures $R_{T}$; but the resistance from the center conductor to the outer conductor in plane $\mathrm{A}$ is $\frac{1}{4} R_{T}=R_{B d c}$. For simplicity we designate $R_{B d c}$ as $R_{B}$. Thus, $R_{\mathrm{B}}$ is the effective dc resistance of the bolometer.

Measuring the de voltage across $R_{T}$ before and after the $\mathrm{rf}$ is applied results in the substituted bias power $P_{B r f}$ :

$$
P_{B r f}=\frac{1}{R_{T}}\left(V_{B 0}^{2}-V_{B 1}^{2}\right)
$$

The rf voltage in plane $A$ is given directly in terms of the dc voltages as follows:

$$
V_{B}=\frac{1}{2}\left(V_{B 0}^{2}-V_{B 1}^{2}\right)^{\frac{1}{2}}
$$

Figure 3 a shows that $V_{r f}$ is the same as $V_{m}$, the voltage applied to the voltmeter, because the input plane to the voltmeter is only 1 or 2 mils away from the bolometer film. Standing-wave effects over a length of 1 or 2 mils even at $36 \mathrm{GHz}$ were shown to be negligible [5].

Figure $3 \mathrm{~b}$ illustrates how to calibrate a current sensor, such as a thermoelement, with the Bolovac. To do this, turn the Bolovac around end for end. The bolometer film (normally voltage output end) is now facing the thermoelement; the distance between the two is kept small to minimize the effect of standing waves. A sliding short (tuning stub), connected to the other end of the Bolovac is adjusted for a maximum value of $V_{B}$. This is facilitated by using a "constant rf current" source, e.g., an rf source in series with a small capacitor. When the combined impedance of the tuning stub, bead and substrate of the Bolovac are equivalent to an integral number of quarter-wave lengths $(n \lambda / 4)$ at a given frequency, all the current passing through the thermoelement is forced into the film. The current $I_{m}$ is given simply by:

$$
I_{m}=\frac{V_{B}}{R_{B}} .
$$

With the Bolovac, thermoelements were calibrated to $2 \mathrm{GHz}$ for the first time at the National Bureau of Standards [5].

The same circuit arrangement and position of the Bolovac as for current measurement is used to apply the Bolovac as a power-absorption mount. This will be discussed further on.

It may be of interest to note that inserting the bolometer and the blocking capacitors into the coaxial line (fig. 2) would not have increased the original effective length of this line except by a negligible amount, were it not necessary to support the bolometer and the center conductor mechanically. Support in. cluded a $3 / 16$-in thick middle plate and a $3 / 16$-in solid substrate. Other versions used a thinner solid bead to support the center conductor and a separate 0.002-in substrate (fig. la). This increased the original line length about $3 / 16$-in. From the practical standpoint, this is not important. However, one may ask what the effect of the resistance or losses in the bead and substrate have on the basic assumption that the powersubstitution principle holds. Momentary inspection of the equivalent circuit (fig. lb) shows that the assumption does indeed hold. The bead and substrate resistances at dc or audio is, for all practical purposes, infinitely large. Therefore, the value of $V_{B}$ is based on the substituted bias power in the film alone and is not affected by the bead and substrate. At microwave frequencies $R_{s}$, in the case of mica, is many orders of magnitude higher than $R_{B}$; thus the likelihood of appreciably heating the film with rf power dissipated in $R_{s}$ may be safely ruled out. It follows that $V_{B}$ is constant at all $\mathrm{rf}$ frequencies irrespective of the rf resistances (or losses) in the bead and substrate because these $\mathrm{rf}$ resistances are effectively in parallel with the film resistance. $V_{B}$ appearing across the film is of course the same across any other resistance in parallel with it. However, the rf losses in the bead and substrate must be considered when the Bolovac is used as a power-absorption mount; but, these losses, as shown later, are of the order of a fraction of a percent and are considered negligible for practical purposes. Also note that narrower beads and other kinds of center-conductor supports (e.g. radial cylindrical pins) can be used.

Figure la shows the position of plane A referred to in figure 2 where the thin bolometric film is located. Keep in mind the critical significance of this plane. $V_{B}$ is measured in this plane. To apply this known $V_{B}$ to any device, (e.g., a voltmeter, oscilloscope, receiver, etc.) the latter should have a coaxial input reference plane mechanically equal to the coaxial cross section in plane $A$ located as close as possible (about 2 mils to $18 \mathrm{GHz}$ ) to plane $\mathrm{A}$. The input coaxial diameters of the device may be different from those in plane A only when it is certain that the voltage in that resultant coaxial step discontinuity is a continuous function and that the electrical field lines remain essentially radial. Because such discon- 
tinuities are avoided in best practices for various reasons (to avoid complex reflection coefficients, additional losses, generation of higher modes, etc.) this case need not be considered further.

Figure 2 also points out that bolometers other than thin films may be used for certain ranges of frequency and magnitude of the quantity measured. For example, the National Bureau of Standards uses 15- to 20-mil diameter thermistor beads for frequencies to $1 \mathrm{GHz}$.

Because the physical size of the Bolovac is affected primarily by the value of $C_{b}$, (fig. 3 ), the dependence of the frequency range on $C_{b}$ is briefly discussed here. Above $100 \mathrm{MHz}$ the required dimensions and structure of the capacitors, $C_{b}$, are best determined by treating the structure as radial transmission lines rather than as lumped capacitors. This avoids resonance effects at some discrete frequencies. At such resonances, unwanted or relatively high impedances might be present in series with a voltmeter under calibration, for example (fig. 2a). Several steps can be taken to avoid such resonances. Stray inductances of the capacitor bolts are minimized by insulating them or replacing them with plastic bolts. Removable auxiliary capacitors can be attached for frequencies below $100 \mathrm{MHz}$. The metallic output plate of the Bolovac can be replaced by a considerably smaller diameter plate for measurements at frequencies above $1 \mathrm{GHz}$. Capacitor diameters were, in this case, estimated using published information $[6,7,8,9]$. However, the uncertainty associated with the termination impedances of these radial lines, required that experimental data be used in determining the adequacy of the assemblies. The characteristic impedance of these radial lines is much smaller than $R_{B}$ and for a given desirable minimum value of $C_{b}$ the smaller the diameter of these capacitors, the better. The objective is to choose diameters safely below those which are equivalent to a one-half wavelength at the lowest frequency used for a given Bolovac output plate. Thus, at frequencies above $1 \mathrm{GHz}$ the outer conductor thickness $(\approx 2 \mathrm{~mm}$ ) of a widely used $50-\Omega$ solid coaxial line was found in our case sufficient. Various designs can, of course, be used instead of the first generation Bolovacs and combinations of the capacitors $C_{b}$ described below. The entire assembly can be reduced radically in size, weight, and cost if the frequency range is above $1 \mathrm{GHz}$. The value of $C_{b}$ should also be correlated with the input impedances of the meters to be calibrated using the Bolovac.

\section{Bolovac Applications}

\subsection{The Bolovac as a Source of Known Voltage}

Various direct applications of voltages above 1 $\mathrm{GHz}$ are listed in the Introduction. The normal voltage-output side of the Bolovac is connected to the input plane of the "unknown" device under test or calibration to apply values of $V_{B}$. Changing frequencies only requires adjusting the $\mathrm{rf}$ input level to the Bolovac to restore bridge balance. Thus, the same $V_{B}$ is obtained for each frequency. Using this procedure in our laboratory, we measured voltage-versusfrequency points at a rate of 20 to 30 per hour using manual adjustment of the frequency and voltage level up to $18 \mathrm{GHz}$. This compares with 2 to 3 hours per poini as quoted by competent technical operators em. ploying the conventional "power-impedance" method. In this latter case, one measures the input power and the input complex impedance of the unknown; the voltage in the input plane is then computed from the two values for each frequency.

To illustrate this application consider measuring the voltage-amplitude bandwidth of a sampling oscilloscope designed to display trapozoidal pulses having rise times as short as 25 picoseconds (ps). A rule of thumb [10] expresses the approximate upperfrequency limit in terms of the rise time;

$$
f_{c}=\frac{0.4}{t_{r}}
$$

where $f_{c}$ is the upper frequency in $\mathrm{Hz}$ at which the uniform amplitude response drops to 0.707 of its medium-frequency value; $t_{r}$ is the rise time in seconds. For a 25-ps rise time $f_{c}$ is $16 \mathrm{GHz}$.

A conceptual setup for this kind of measurement is described (fig. 4). The Bolovac can have any bolometer resistance that will furnish a typical input $V_{B}$ to the oscilloscope, e.g., $0.1 V$. If the Bolovac out-

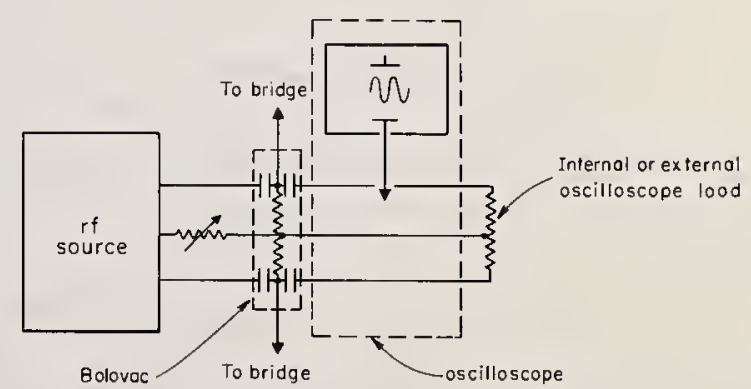

FIGURE 4. Measurement of voltage amplitude bandwith of oscilloscope with a Bolovac. 
put voltage is held constant irrespective of the load impedance, $Z_{L}$, attached to it (in this case the input impedance of the oscilloscope), the effective internal impedance of the Bolovac is zero (by Thevenins theorem). Sinusoidal-waveform amplitudes on the oscilloscope CRT are observed as they vary with frequency. This procedure is useful for calibrating other voltage-dependent instruments in the frequency domain, such as voltage spectrum analyzers, voltmeters, field-strength meters, etc.

In most cases, instruments operate from rf sources having a given fixed internal impedance, $Z_{O}$, e.g., $50-\Omega$ at all frequencies for a $7-\mathrm{mm}$ coaxial system. In these cases the zero-impedance Bolovac renders an accurate frequency response only if the input impedance of the instrument is $50-\Omega$ at all frequencies. One must, of course, divide the indication of the instrument under test (assumed to be linear) by two to obtain the correct response. This is so because a source of $V_{B}$ with two $50-\Omega$ resistors (one inside the source and the other in the instrument input) will reduce $V_{B}$ by 50 percent when it is applied to the instrument.

Unfortunately instrument input impedances at these frequencies are seldom $50-\Omega$ and are even less likely to remain constant with frequency. The best solution in these cases is to use a $50-\Omega$ coaxial resistor in series with the Bolovac output. At the present state-of-theart several such resistors will be required, each covering a certain frequency range.

Another way of expressing the frequency response of the unknown in terms of an ideal source having an internal impedance of $Z_{o}$ is to measure the complex $Z_{L}$ at each frequency and to compute the internal voltage of the ideal generator, $e_{g}$, in terms of the measured $V_{B}$.

$$
e_{g}=V_{B}\left[\frac{\left(Z_{O}+R_{s}\right)^{2}+X_{s}^{2}}{R_{s}^{2}+X_{s}^{2}}\right]^{\frac{1}{2}}
$$

where $R_{s}$ and $X_{s}$ are the series resistance and reactance respectively of the unknown. One may use a sweep frequency technique to measure the impedance of the unknown and a desk calculator to compute $e_{g}$; however, it is apparent that a single coaxial resistor having constant resistance over the desired frequency range will eliminate all these measurements and computations.

A third solution is to employ a high-resistance film, e.g., $R_{s}=5000 \Omega$. In this case the Bolovac connects into $\mathrm{rf}$ and microwave systems as any high resistance voltmeter would at low frequencies.
An additional illustration may help point out the wide range of applications where the Bolovac serves as a source of known microwave voltages. Consider a hypothetical problem where one needs to generate a relatively high electric field to determine the break. down characteristics of a coaxial line or of a lumped miniature component. Conventionally one might use a high-power source feeding a coaxial line terminated in its characteristic impedance. This method requires considerable amount of power to generate high voltages. On the other hand one may apply a known, relatively low value of $V_{B}$ to the Bolovac at the input to a coaxial line whose output is open circuited. High voltages are then produced in the line with relatively low power. The voltage values in the line are given in terms of $V_{B}$ and the voltage ratios along the line can be measured in a conventional manner.

It would be feasible to design direct-read-out electronics for $V_{B}$ and $P_{B}$, the rf power dissipated in the bolometer disk of the Bolovac. However, the graphical method shown in figure 5 avoids most of the computations [4]. One can draw a quadrant of a circle

$$
\begin{aligned}
& V_{f f}=V_{B}=\frac{1}{2}\left(V_{B O}{ }^{2}-V_{B 1}{ }^{2}\right)^{\frac{1}{2}} \\
& V_{B O}\left(V_{B 1}\right)=d c \text { volloge ocross the bolometer without (with) if opplied fo it }
\end{aligned}
$$

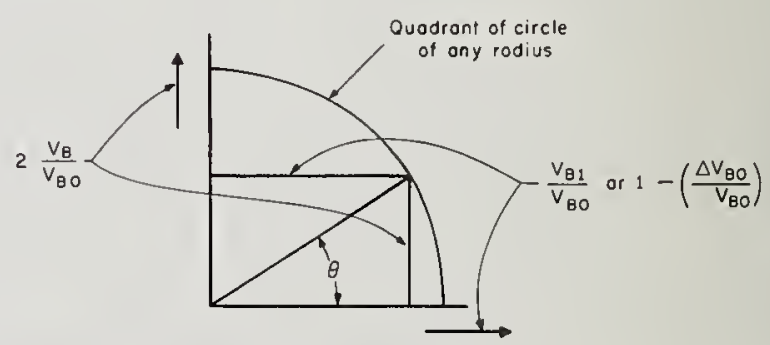

Or use Sine - Cosine irigonometric fobles

FIguRE 5. Graphical determination of $V_{\mathrm{B}}$.

having a relatively large diameter on linear squarecross-section graph paper. For each ratio of $V_{B 1} / V_{B O}$ or of $\left(1-\Delta V_{B O} / V_{B O}\right)$ on the $\mathrm{X}$ axis there is a corresponding value of $2 V_{B} / V_{B O}$ on the $\mathrm{Y}$ axis. $V_{B}$ can then be determined without squaring and taking roots of values. High precision requires trigonometric tables in which one simply finds the cosine of the angle, $\theta$, equal to $V_{B 1} / V_{B O}$ or to $\left(1-\Delta V_{B O} / V_{B O}\right)$. The sine of the same angle $\theta$ yields the ratio of $2 V_{B} / V_{B O}$ and

$$
V_{B}=\frac{1}{2} V_{B 0} \sin \theta .
$$

The potential accuracy of $V_{B}$ can be computed by any user in terms of his equipment accuracies. As is 
seen from eq (4) and the preceding discussion, the accuracy of $V_{B}$ depends primarily upon the accuracy of the dc voltages. When estimating accuracies, care should be taken as $V_{B 1}$ approqaches that of $V_{B O}$ or when $V_{B 1}$ is a small fraction of $V_{B \cdot 0}$. The uncertainties in the values of $V_{B}$ of the order of a fraction of a volt to several volts in our experimental work were estimated at a couple percent to $18 \mathrm{GHz}$ and better at lower frequencies; e.g., \pm 1 percent at $1 \mathrm{GHz}$; these uncertainties are based on the agreement of the results with the power-impedance method. Because the Bolovac results depend primarily on dc measurements, they are felt to be more accurate than the agreement sited above.

\subsection{The Bolovac for Measuring Power}

The advantages of the Bolovac for power measurement are indicated in the Introduction. Its major contributions in this respect are eliminating the effects of serious termination mismatch errors and the errors accumulated in a chain of three or more calibrations by laboratories passing rf power standards from one laboratory to the next. The Bolovac, as was pointed out, needs no rf calibration. It operates in two modes; the voltage mode and power-absorption mode. In measuring power the Bolovac can do one of three things: (1) measure the rf voltage across a known resistive component of a given load; (2) measure the rf voltage in any plane of a coaxial line of known characteristic impedance, $Z_{0}$, and known voltage distribution along this line; or (3) absorb the rf power as any other absorption-type power mount does. In the first two cases load resistance and voltage-distribution measurements can be made separately without the Bolovac, or these measurements can be combined with the power-measurement procedure employing the Bolovac. In the third case the rf power is, for all practical purposes, absorbed entirely by the bolometric film and is equal to the biasing power substituted in the film. Any appreciable unaccounted-for losses of net power flow from a source to the Bolovac occur outside the Bolovac and can be determined by employing conventional techniques as well as the Bolovac itself. This is not the case with most present-day absorption mounts where the internal losses which go undetected by their sensors are appreciable and must be calibrated out in terms of rf-power standards [11]. The Bolovac's superiority rests in the fact that it measures power in terms of relatively well controlled and measured parameters, namely dc (or audio) quantities, characteristic im- pedance of coaxial lines, $Z_{0}$, and ratios of $\mathrm{rf}$ voltages $[3,4]$. This is in contrast to complex reflection coefficients of sources and loads, efficiency factors and $\mathrm{rf}$-dc substitution factors with reference to standard calorimeters. Sources of dc having accuracies an order of magnitude better than for rf are widely available; so are good quality coaxial lines having an accurately known $Z_{0}$. Rf-voltage ratios can be measured with much higher accuracies than their absolute values as is true for ratios of most other quantities. It follows that the potential accuracy of measuring power with the Bolovac approaches the accuracy of measuring the substituted bias power. Thus, the Bolovac can be considered a new type power-absorption mount; among the other unique attributes it also includes an rf output in addition to the $\mathrm{rf}$ input connector not found on conventional mounts. This structural feature enables several Bolovac applications described below.

As with rf voltage, the policy was to assign a conservative value of several percent to the uncertainty of measuring milliwatt levels with the Bolovac at 18 $\mathrm{GHz}$. Such policy stems from the limited agreement with conventional methods of power measurement.

Though the Bolovac is a superior standard of power for the best of laboratories, our main objective is to encourage its application in all lower-echelon laboratories as well as field measurements. Its use by lowerechelon personnel can reduce uncertainties from about 25 percent, and higher as frequency increases, to about two percent. The objective is not to reduce uncertainties to fractions of a percent but to achieve a significant reduction with dramatically reduced efforts compared with present practice.

One of the objectives of measuring power is to evaluate the quality of a power source, i.e., to find the maximum net (incident minus reflected) power delivered to a load. In this case the load impedance must be the "conjugate" of the source impedance; in other words, the load $(L)$ resistance, $R_{L}$, must be equal to the source resistance, $R_{s}$, and the load reactance, $X_{L}$, must be equal and 180 degrees out of phase with the source reactance, $X_{s}$. Analytically stated, it is required that

$$
R_{L}+j X_{L}=R_{s}-j X_{s}
$$

This condition is generally realized by connecting a three-stub tuner between the source and the load; the stubs are adjusted for maximum power indication in the load, designated as $P_{c}$ into a "conjugately matched" load.

Another index of source quality is the net power $P_{o}$ delivered to a load having a VSWR $=1$. In this case 
standing waves are nonexistent in a coaxial line connecting the source and the load, provided $Z_{0}$ of the line equals $Z_{L}$. In practice $Z_{O}$ is resistive and a threestub tuner connected in front of the load is adjusted for a "Z $Z_{o}$ match". A slotted line ahead of the stub tuner allows one to observe the flatness of the voltage distribution. A relatively simple procedure that accomplishes this is described in appendix $\mathrm{C}$ of [3].

Still another objective in measuring power is to find the net power, $P_{n}$, flow from a source to a load under any matching conditions. Basic schematic diagrams and steps of procedure are outlined below to measure $P_{c}, P_{o}$ and $P_{n}$ using the Bolovac as a source of known rf voltages at frequencies up to $18 \mathrm{GHz}$ and potentially to $36 \mathrm{GHz}$. In all these cases the losses in slotted lines are assumed negligible. However, these losses as well as losses in stub tuners and other components can be measured with the Bolovac as will be discussed later. The special case of measuring incident power is discussed briefly later on.

\section{a. Power Measurement with Bolovac Operating in the Voltage Mode}

This method is particularly attractive with the advancing art of automating VSWR measurements.

Two well-known equations are used in this case [3]:

$$
\begin{aligned}
& P_{n}=V_{s}^{2} / R_{L} \text { and } \\
& P_{n}=V_{\max }^{2} / S Z_{O}=\left(V_{B} \frac{V_{\max }}{V_{B}}\right)^{2} / S Z_{O}
\end{aligned}
$$

where

voltage magnitudes are used.

$$
\begin{aligned}
P_{n}= & \text { net power flow to load } \\
R_{L}= & \text { is the parallel resistive component of the } \\
& \text { load impedance } \\
V_{\max }= & \text { the maximum voltage in a slotted coaxial } \\
& \text { line connected between the Bolovac and } \\
& \text { the load. } \\
S= & V_{\max } / V_{\min } \text { in the slotted line }=\mathrm{VSWR} \\
Z_{0}= & \text { the characteristic impedance of the } \\
& \text { slotted line (Note that once } V_{B} \text { is known } \\
& \text { only the ratio } V_{\max } \text { to } V_{B} \text { needs to be } \\
& \text { known instead of the actual value of } \\
& \left.V_{\max .}\right)
\end{aligned}
$$

(1) Evaluation of Source of RF Power. For sake of simplicity the symbols shown in figure 6 designate setup components in this and the following figures.

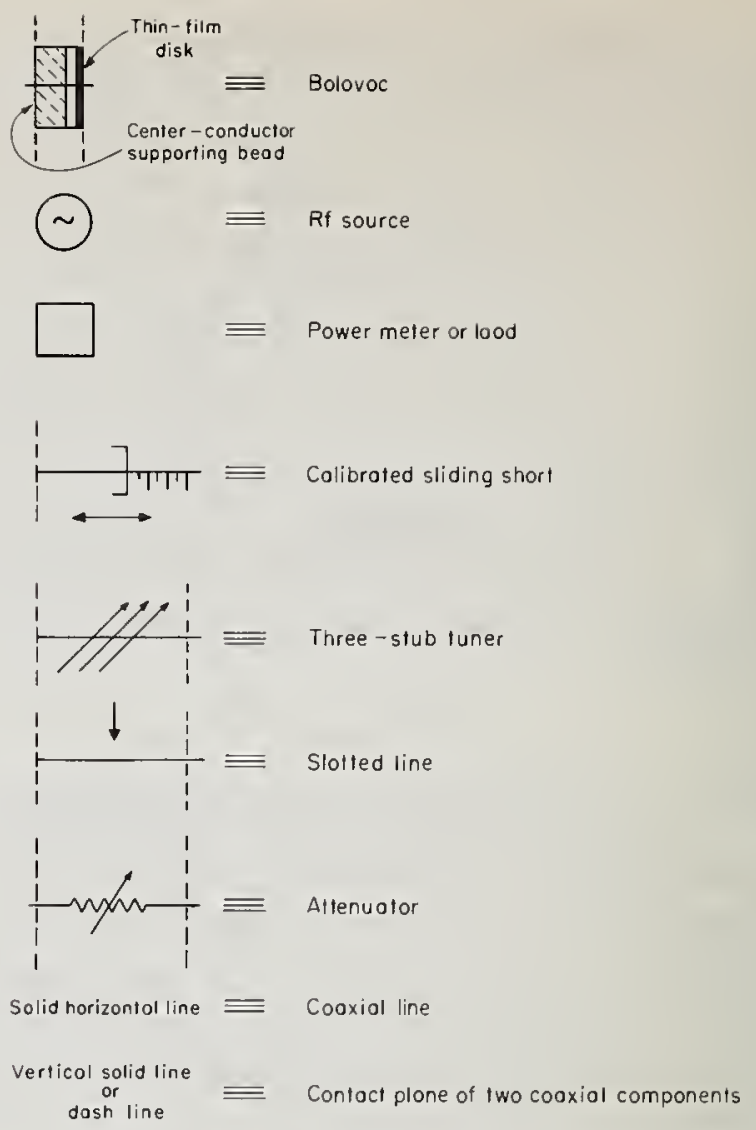

Figure 6. Symbol designations unless otherwise labeled.

The maximum available power, $P_{c}$, of a source can be measured using the Bolovac as a voltmeter by a substitution method in two steps (fig. 7) [3]. However, attention is called at once to a much simpler method of measuring $P_{c}$ using the Bolovac as an absorption mount as described in the next section. In the first step of the voltage mode adjust the threestub tuner for a maximum indication of any power meter serving as a load. Let its maximum reading be $D_{1}$. In the second step, feed a Bolovac from any other source in series with the slotted line; this source
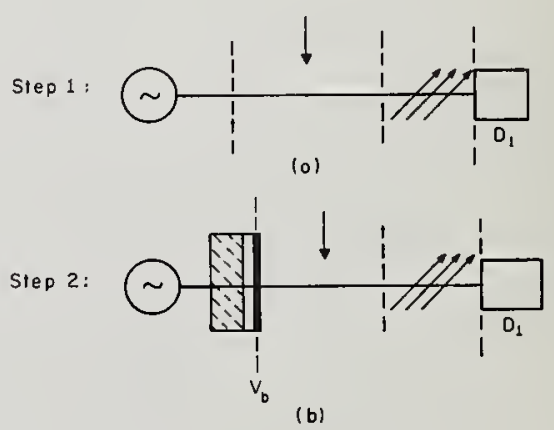

$$
P_{c}=\left(V_{B} \frac{V_{\text {max }}}{V_{B}}\right)^{2} / S Z_{\theta}
$$

Figure 7. Measurement of $P_{\mathrm{c}}, P_{\mathrm{o}}$, and $P_{\mathrm{n}}$ with the Bolovac used as a voltmeter.

(See a simpler method for $\mathrm{P}_{\mathrm{c}}$ and $\mathrm{P}_{\mathrm{o}}$ with the BOLOVAC operated in the power-absorption mode.) 
and the Bolovac substitutes for the original source under test; in other words they improvise a source equivalent to the original. Adjust the frequency and output of the source to reproduce $D_{1} . P_{c}$ is then given by equation (11). To measure the ratio $V_{\max } / V_{B}$ locate the plane in the slotted line which is located an integral number of half-wavelengths, $n \lambda / 2$, away from the output plane of the Bolovac. It is most important that the output plane of the Bolovac be located at the input plane of the slotted line, also that there be no appreciable discontinuities between this plane and any other plane in the slotted line where voltage ratios are measured. Good quality commercial lines meet this requirement; it can be readily checked by comparing (1) the physical distances from the input to the line and inside planes with (2) the electrical wavelengths at several frequencies. These distances can be predetermined (once) for each frequency in terms of the graduated scale of the slotted line. Thus, the position of $V_{B}$ inside the slotted line is known and its magnitude is generally equal to that measured by the Bolovac because the losses in the line are negligible for practical purposes. However to be safe one should make voltage-ratio measurements at the Bolovac end of the slotted line. The losses at the other end, if any, and of the stub tuner need not be considered in this case. Replacing a power meter or other indicating device with a dummy load allows an auxiliary $\mathrm{CW}$ probe to be employed in the slotted line to reproduce a reading $D_{1}$ in any fixed plane in the two steps. If the modulation characteristics of the unknown and the source in step 2 are the same the VSWR meter may be used for this purpose; using the $C W$ probe entirely eliminates modulation needs and problems.

The relative merits of this method compared to the Bolovac as an absorption power meter is in that it may eliminate the need to terminate the Bolovac in a sliding short. This will be discussed later.

The $Z_{o}$-matched power output of a source is measured employing the same two steps as for $P_{c}$, except the three-stub tuner in the first step is adjusted for a flat voltage distribution in the slotted line.

To measure the net power flow, $P_{n}$, from any source to any load, the first step consists simply of the original system [3]. The system must not be disturbed. However, when reproducing the power-flow condition in the second step some kind of monitor is required that will not upset the impedances and voltage dis- tributions in the original step 1 . If the load is a power meter, its panel-meter reading is used; if the load is an antenna, a loosely coupled receiver or detector may be used. In many cases field leakage picked up by a sensitive receiver will serve as a monitor. Where a transmission line is present between the sources and the load, the line should be considered part of the load and its input plane should be connected to the output end of the slotted line in step 2 .

(2) Power-meter Calibration. When calibrating a power meter using the Bolovac as a voltmeter first measure the equivalent parallel resistive com. ponent of the power meter, $R_{p}$, with any conventional method. Then connect the power meter to the normal voltage output of a Bolovac (fig. 8-b) and the net rf power is given by $V_{B}{ }^{2} / R_{p}$. Using a slotted line as shown in figure 8-a for this purpose, we have

$$
R_{p}=S Z_{o}\left(V_{m} / V_{\max }\right)^{2}
$$

where $V_{m}$ is the voltage at a plane in the slotted line $n \lambda / 2$ away from the plane of contact between the slotted line and the input to the power meter. Im. pedance charts to find $R_{p}$ are unnecessary and the equivalent reactive component $X_{p}$ is neglected because it does not absorb power as is evident from figure 8-b. The accuracy of $R_{p}$ depends on the accuracy of $Z_{O}$ and of two rf-voltage ratios. It is also important here that the coaxial slotted line have no discontinuities between the plane of $V_{m}$ and the input plane to the power meter.
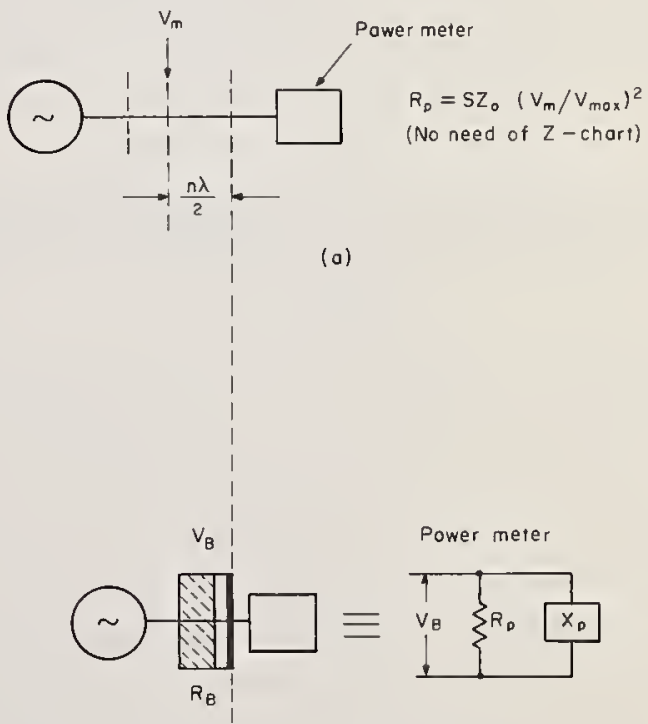

(b)

Figure 8. Calibration of power meter in two steps with Bolovac operating in the voltage mode. 


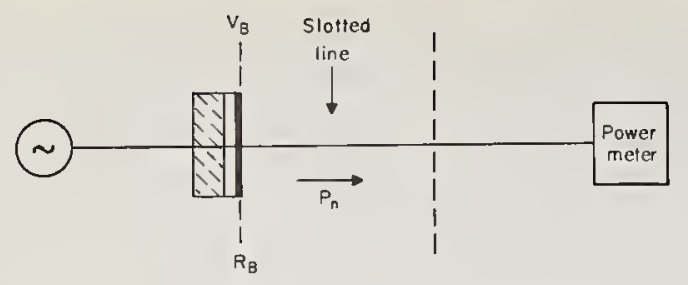

$P_{n}=\left(v_{B} \frac{V_{\operatorname{mox}}}{V_{B}}\right)^{2} / S Z_{0} \quad$ (No need computing $R_{p}$ )

or

$$
P_{n}=\frac{\left(V_{B O}^{2}-v_{B !}^{2}\right)}{4 S Z_{0}\left(\frac{V_{m}}{V_{m o x}}\right)^{2}}
$$

FIGURE 9. Calibration of power meter in one step with Bolovac operating in the voltage mode.

Locating the slotted line between the Bolovac and the power meter is another way to calibrate the power meter (fig. 9). In this case the net power flow from the Bolovac to the power meter is measured and knowing the value of $R_{p}$ is unnecessary. $P_{n}$ is given by eq (11).

It is possible to compute the value of the "effective efficiency", $\eta_{e}$, and the "calibration factor", $K_{c}$, usually furnished by the manufacturer as corrections to its panel meter readings [3]. This may be desirable in acceptance tests. These corrections are defined as:

$$
\begin{aligned}
\eta_{e} & =\frac{\text { Substituted bias power }}{\text { Net rf power dissipated in the mount }} \\
K_{c} & =\frac{\text { Substituted bias power }}{\text { Power incident on the mount }}
\end{aligned}
$$

The user must in this case calibrate the commercial mount for substituted bias power. Then $\eta_{e}$ is given directly in terms of the $P_{n}$ obtained with the Bolovac. The power incident on the mount is given by [3]

$$
{ }_{j} P=P_{n}(S+1)^{2} / 4 S .
$$

\section{b. Power Measurement Using the Bolovac as a}

\section{Power Absorbing Mount (Power-absorption Mode)}

Considered a new type of power-absorbing mount the Bolovac differs from most of the present conventional mounts in several important respects. In this application the normal voltage-output side of the Bolovac is connected facing the rf source. The other side of the Bolovac may be left open permitting some power to be transmitted beyond the Bolovac film. Therefore, the other side may be left open when this power loss is negligible or it may be terminated in a tube that extends the outer conductor so to reduce radiation by shielding, or it may be terminated in a sliding short to tune out residual internal reactances of the Bolovac. The sliding short, calibrated once for positions of the piston versus frequency, is connected as in figure 10 ; the piston is then preset to the position corresponding to the appropriate frequency with-

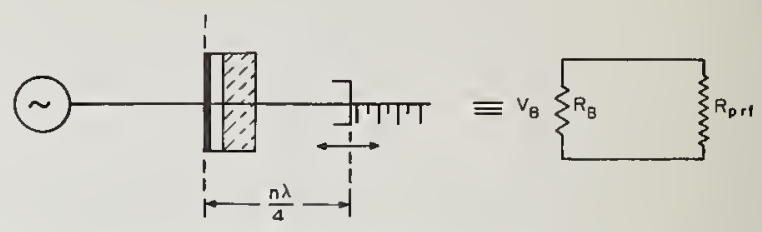

Figure 10. Application of the Bolovac as an absorption type power mount.

The sliding short may be replaced by a shielding tube or may be eliminated, depending on the frequency and requirenents. Note that the thin film is now facing the source.

out tuning for each measurement. The major differences between the Bolovac and present conventional mounts are as follows:

--The bolometer of the Bolovac entails no rf-for-dc substitution error. It has no lead inductance and for all practical purposes its rf impedance equals its dc resistance at all frequencies mentioned above.

--It has an input port as well as an output port, which allows one to tune out internal residual reactances when necessary.

--The bolometric film can be placed to within a couple of mils directly in the plane of the output of a source. It therefore has no input "connector" in the ordinary sense of this term. Its output plane is electrically in the plane of the film; $R_{p r f}$ (fig. 10) is the equivalent antiresonance resistance of the sliding short including the losses in the bolometer substrate and whatever supporting beads are used in the Bolovac and sliding short assembly. $R_{B}$ for this application is generally of the order of $Z_{0}$ (e.g., 50- $\Omega$ ) or less and $R_{p r f}$ is much larger than $R_{B}$. Sliding shorts were constructed at the National Bureau of Standards having $R_{p r f}$ effective values of $200 Z_{o}$ or higher at $18 \mathrm{GHz}$. Therefore, for practical purposes the power absorbed by the Bolovac can be made to equal without any corrections $V_{B}{ }^{2} / R_{s}$ to within a couple percent or better at all frequencies up to $18 \mathrm{GHz}$.

-Because the Bolovac has an input and output port the losses of any other components used in the power measurement setup are external to the Bolovac and can be measured independently if 
accuracies better than a couple percent are required. In addition, these two ports make it possible to measure the internal losses of the Bolovac itself, if they are of any consequence. A way of measuring these losses is discussed later.

Thus, the three major sources of errors, i.e., (1) dc-to-microwave substitution error (2) appreciable rf losses and (3) the termination mismatch requiring individual $\mathrm{rf}$ calibration of conventional power mounts $[11,12,13]$, can be eliminated by applying the Bolovac.

(1) Bolovac as Absorption Mount to Evaluate Quality of RF-Power Source. Figure 11 illustrates the setup to measure $P_{c}$. It was pointed out that this method of measuring $P_{c}$ is simpler than the one that uses the Bolovac voltage mode. A slotted line or an additional power meter shown in figure 7 is not required. The procedure here is to adjust the stub tuner for maximum $V_{B}$, i.e., for maximum bias power to be removed from the Bolovac while maintaining its bridge balance. $R_{B}$ need not be equal to $Z_{O}$ (e.g., $50-\Omega$ ) and the residual internal reactances of the Bolovac need not be tuned out because no power is dissipated in them. The losses in the stub tuner are determined by a method described below in the section on measuring insertions loss of components. Equation (3) is used to compute $P_{c}$. An important assumption throughout this paper is that stable sources are used and that their $P_{c}$ is constant at any given frequency.

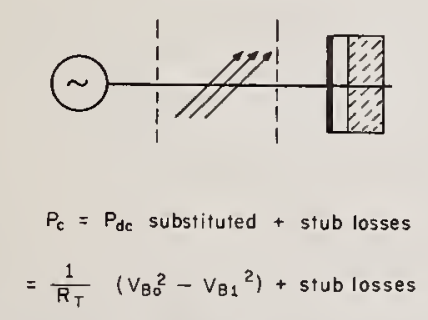

FiguRE 11. Measurement of maximum available power from a source with the Bolovac as an absorption power mount.

The best way to measure $P_{O}$ of a source using the Bolovac as an absorption mount is to use a Bolovac having $R_{B}=Z_{O}$, and a sliding short as shown in figure 10. When $R_{B}$ does not equal $Z_{o}$ a slotted line and a three-stub tuner must be used (fig. 12). A sliding short is not needed. The stub tuner is first adjusted for a flat voltage distribution in the coaxial line and $P_{o}$ is measured next as was $P_{c}$. One may, of course, adjust the stub as a separate preliminary step and remove the slotted line to measure $P_{0}$, provided

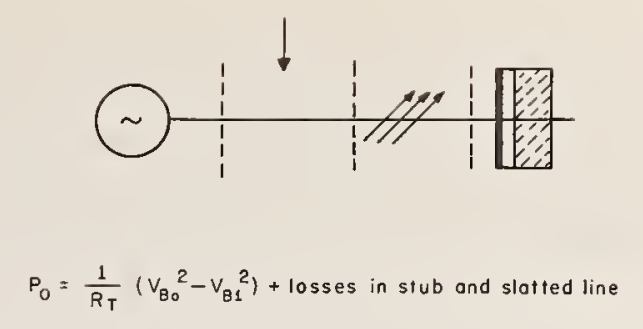

Figure 12. Measurement of $P_{0}$ with Bolovac as an absorption mount.

that the impedance looking into the stub tuner is $Z_{O}$ when the line is removed.

By improvising an equivalent rf-power source employing a Bolovac operating in the voltage mode one can measure the net power flow, $P_{n}$, from any source to any load (fig. 7). Although it may seem too complicated, it is not impossible to improvise an equivalent load using a Bolovac. To do this one must measure the equivalent parallel input resistance and reactance of the load, and then reproduce corresponding values of $R_{B}$ of a Bolovac and shunt it with a reactance equal to the load reactance. $R_{B}$ values are varied by changing the bias on the Bolovac bolometer within certain ranges that are limited by its safe power dissipation and its bolometric constant, $\gamma$, the change in ohms per watt of dissipated power. Once the correct value of $R_{B}$ is obtained a sliding short at the output of the Bolovac can be adjusted to reproduce the value of $S$ observed with the original load. $P_{n}$ can then be measured using this terminated Bolovac by connecting it directly to the given source in place of the original load; the substituted bias power is the desired answer.

(2) The Bolovac as an Absorption Mount to Calibrate Power Meters. A power meter can be calibrated by substituting it with a Bolovac in a setup measuring $P_{c}$ of a stable rf-power source (fig. 11). First, measure $P_{c}$ of the given source using the Bolovac as described above. Second, use the power meter in place of the Bolovac and adjust the stub tuner for a maximum power-meter reading. Power absorbed by the power meter equal $P_{c}$ measured by the Bolovac. If $R_{B}$ is of the same order of magnitude as the power-meter input impedance the loss in the stub tuner will remain the same for practical purposes; otherwise it may be necessary to determine the difference and introduce a correction.

(3) Calibration of Low-level Signal Generators Using the Bolovac in the Power-absorption Mode. There are two kinds of rf signal generators. One furnishes standard voltages at its output plane provided that the load impedance connected to it is 
two or more orders of magnitude larger than the generator's internal impedance. The upper frequency of these generators is seldom more than $30 \mathrm{MHz}$.

The others are designed to work into matched loads and are calibrated in terms of voltage appearing across the matched load, or power absorbed by such loads. The upper frequency of these generators reaches into the microwaves. Many or most of the second kind are calibrated in terms of both voltage and power. This difference in calibrating present conventional generators seems to introduce unnecessary confusion without justification; the calibration may be made in power alone assuming the ideal objective to be source and load impedances that equal $Z_{0}$.

Calibration procedures for the first kind of generators are extensively covered in the literature. The case of the second kind is discussed here because the approach has some attractive aspects.

One should keep in mind, however, the possible application of the Bolovac as a voltage source (as described above) to evaluate pulse-display oscilloscopes. In that case the Bolovac is treated as a zero-impedance voltage source (with or without a series matching resistor) similar to low-resistance rf Micropotentiometers [14].

In case of signal generators delivering output levels corresponding to $0.1 \mathrm{~V}$ or higher, the signal generator is calibrated at the maximum output, employing any of the methods described above. Specifications generally call for a load of $Z_{0}$; therefore a Bolovac having $R_{B}=Z_{O}$ and its output terminated in a sliding short, is preferable. Other $R_{B}$ values may be used with a three-stub tuner to present a $Z_{o}$ load to the signal generator.

For lower outputs one may take advantage of the presence of the sliding short as shown in figure 13 . A loosely coupled probe is combined with the sliding short and its output is fed to a sensitive receiver in series with an external standard attenuator, A. Starting with a high attenuation setting of $\dot{A}$ and maximum output of the signal generator (measured by the Bolovac), the settings of the internal attenuator of the signal generator are calibrated by substitution in terms of $A$, keeping the indication of the receiver, $D_{1}$, constant. The advantage of this setup is that once assembled, the entire calibration may be performed without moving any of the components. The presence of the probe need not reduce the effectiveness of the sliding short appreciably. A slotted line with its sliding probe may be used in series with the sliding short; its probe may then be set at any plane of the sinusodial distribution of the voltage in the slotted line

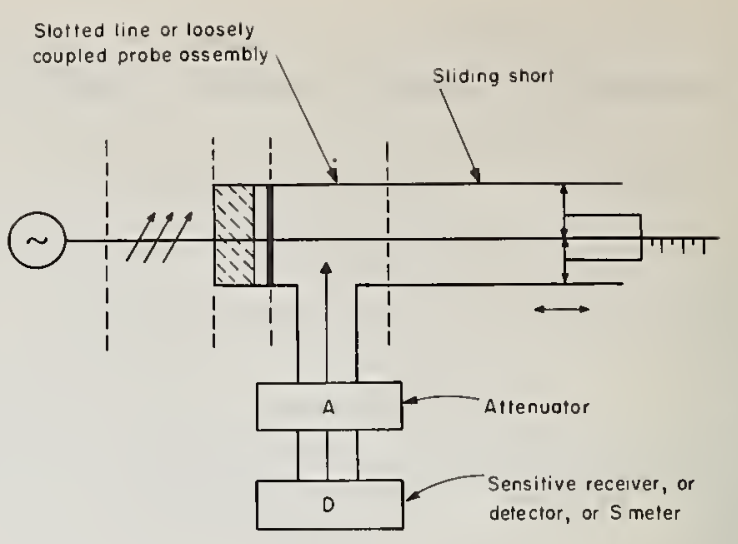

Figure 13. Carrier output calibration of low-level signal generators employing Bolovac in the power-absorption mode of operation.

to do two things: (1) to vary the voltage pickup of the probe if necessary, and (2) to serve as another calibration of voltage-ratios and as a double check on A. One may also make use of the sinusoidal distribution of the voltage to calibrate the internal attenuator when a standard attenuator is not available.

Throughout this procedure, it is best to keep the Bolovac bridge balanced (by increasing the bias power as the rf-signal power is decreased) to keep the load on the signal generator constant; this may be important at high output levels and negligible at low levels.

\subsection{The Bolovac as a RF-current Standard}

Figure 3-b, a schematic for this application differs from $3-\mathrm{a}$ in that a constant-voltage bridge is shown in the latter and a constant-current in the former. The rf current in the current sensor is given by $V_{B} / R_{B}$, or is computed in terms of the bridge currents [5]. The basic principle involved here was discussed previously. One may add that any current sensor at the frequencies in question must be treated as an integral part of its assembly including the shielding enclosures located between defined input and output planes. The Bolovac measures current flow in the center conductor at the output plane of the current-sensor assembly. One must keep this in mind when designing the normally voltage-output plate of the Bolovac to provide proper connection facilities. It is evident that the higher $R_{B}$ is, the lower are the rf currents that can be measured and vice versa. Current standardization is particularly important in evaluating current-pulsedisplay instruments for fast-rise-time pulses having microwave-current components. 


\subsection{Application of the Bolovac for Insertion-loss Measurements}

A practical way to determine rf losses of components, such as three-stub tuners, slotted lines, adapters, etc., is to measure the power $P_{c}$ absorbed by a Bolovac (or a precalibrated power meter) supplied from a stable rf source, i.e., a source having a constant $P_{c}$. A three-stub tuner must be used to begin with, when $P_{c}$ is measured as in figure 11 . Nonadjustable components, such as a slotted line, are simply inserted into the setup; the stub is retuned for maximum indication of the Bolovac and the loss equals the difference between the two values of the measured $P_{c}$. An uncertainty is introduced by the limited reproducibility of connector contacts and the difference and reproducibility, in the losses of the different plunger positions of the three-stub tuners. Our experience indicates that this uncertainty is, for practical purposes, negligible when reasonably good-quality commercial components are used. The user may of course perform a number of repeated measurements and establish a reproducibility figure statistically. Adjustable components, such as stub tuners, can be treated the same way. It seems unnecessary to use exact duplicate components for this purpose. $P_{c 1}$ can be measured with a stub manufactured by $X$, and $P_{c 2}$ with an additional stub manufactured by $Y$. The difference $\left(P_{c 1}-P_{c 2}\right)$ represents the loss of the stub inserted last. Because the contact resistances of stubtuner plungers can have poor reproducibility, the limits of uncertainty for the losses of any one threestub tuner can be measured by setting the plungers at various positions to obtain a maximum possible error; the number of possible positions yielding a maximum power reading, as is well known, approaches infinity. Using a precalibrated commercial power meter might be more convenient and may prove equally reliable because the ratio $P_{c 1} / P_{c 2}$ is considerably more accurate than either one of these values.

The significance of the losses in the sliding shorts can be checked conveniently in combination with the Bolovac in preference to measuring their high input VSWR without the Bolovac. Figure 8-a and equation (12) are used in this case. The $R_{p}$ values of the Bolovac are measured with and without connecting the sliding short and yield the answer of interest in power measurement. Equations (4) and (10) and the measured value of $R_{p}$ will yield the correct $P_{n}$. The rf level used for this measurement should be kept low enough not to affect $R_{B}$; otherwise, it is necessary to keep the Bolovac bridge balanced at each measurement.
The significance of the internal losses of a Bolovac can also be checked by treating it as a component. The only difference is that a "dummy" Bolovac of the given design should be used in which the film has been omitted. Thus one measures any possible residual losses of the structure including those of the substrate, the supporting element of the center pin, and possible radiation losses through the blocking capacitors (fig. 3).

\subsection{Self-evaluation of the Bolovac}

The Bolovac's two operational modes enable measuring its own internal losses and detecting other internal irregularities within the limits of resolution of the associated equipment. Its voltage output, $V_{B}$, is not affected by its internal losses no matter how large they might be. On the other hand the power absorbed by the Bolovac as an absorption mount is of course affected by its losses. Therefore, one can measure a fixed value of $P_{c}$ by the two operational modes (figs. 7 and 11) and compare the two results after correcting for residual losses in the slotted line of figure 7. Figure 14 shows the steps more clearly. Step (a) establishes a reference reading, $D_{1}$, of any power meter corresponding to $P_{c}$ of the given stable source. Step (b) calibrates the value of $P_{r}$ in step (a) operating

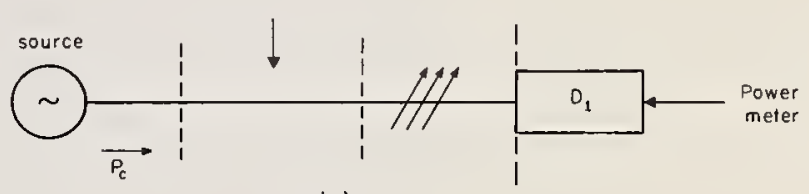

(a)

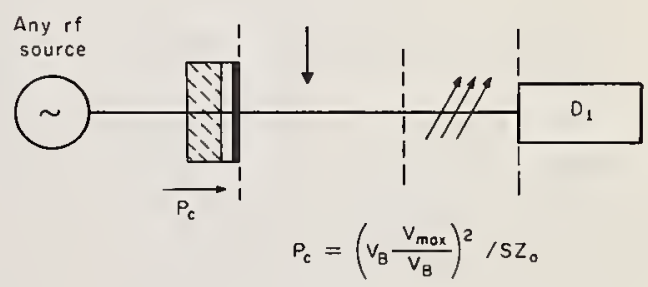

(b)

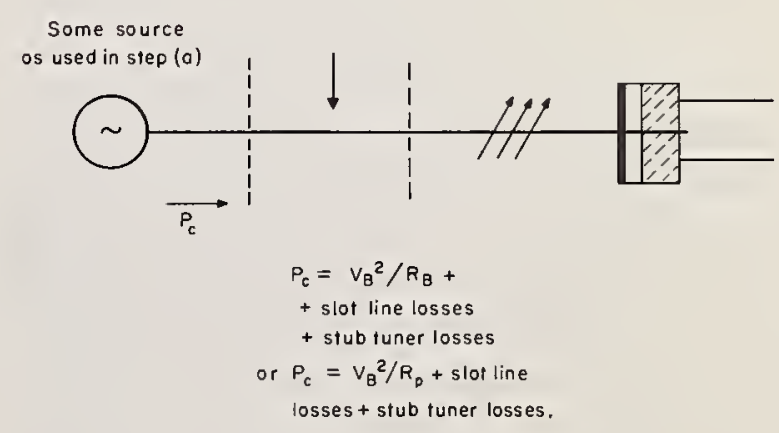

(c)

Figure 14. Self checking of Bolovac. 
the Bolovac in the voltage mode. Step (c) measures $P_{c}$ of the same source operating the Bolovac in the power-absorption mode. The method for determining the slotted-line and the stub-tuner losses have been described earlier. The values of $P_{c}$ obtained in steps (b) and (c) should of course be the same. Chances are that no difference will be detectable using well constructed Bolovacs except perhaps at the very upper frequencies of the range indicated. On the other hand large differences point to improper assembly or other defects in the Bolovac.

Another way to check Bolovac quality is to measure the resistive component of the Bolovac input impedance when terminated in a shielding tube. Equation (12) yields the value of the $R_{p}^{\prime}$ of the Bolovac when no appreciable losses are present. In case $R_{p}^{\prime}$ is different from $R_{B}$ it can be used instead of $R_{B}$ to compute the power absorbed by the Bolovac, i.e.,

$$
P_{n}=V_{B}^{2} / R_{p}^{\prime}=\frac{1}{4}\left(V_{B 0}^{2}-V_{B 1}^{2}\right) / R_{p}^{\prime} .
$$

\subsection{Other Bolovac Applications}

Because $R_{B}$ is known and remains constant at all frequencies to $18 \mathrm{GHz}$, the input impedance looking into the Bolovac voltage-output port for power absorbing connection, equals $R_{B}$ provided the losses of sliding-short when connected to the other side of the Bolovac (fig. 10) are negligible. The residual losses of the film substrate and center-conductor supporting bead of the Bolovac itself are assumed negligible. Provided this condition on the losses holds, the Bolovac serves as a known impedance at all frequencies for various applications; e.g., as a match or mismatch termination over an unprecedented frequency range for impedance, attenuation, residual VSWR of slotted lines, and other measurements. Moreover, its magnitude can be varied over a range of values depending on the film characteristics and can be kept constant to a high precision by adjusting its bias.

With proper adapters the Bolovac can be used to measure power in single-conductor transmission systems operating in any mode. Adapter losses are determined as described earlier, using adapter pairs.

High-resistance $\left(R_{B} \geq 1000 \Omega\right)$ Bolovacs can be used to monitor net power flow in systems during operation. Because the bolometer consumes a small fraction of the net power, these power levels are limited by its power dissipation capabilities. The net power flow can exceed a kilowatt. A notable advantage in such an application is the high sensitivity of the Bolovac as a detector of small variations in the load impedance of the system. Such variations are readily detected as the voltage in the plane of $V_{B}$ is changing, whereas they are not detected when reading, for example, traditional side-arm power meters of directional couplers. A high- $R_{B}$ Bolovac can be connected into a system permanently or temporarily with a slotted line and operates at all frequencies up to $18 \mathrm{GHz}$ as compared to the limited frequency ranges of directional couplers.

The Bolovac can be connected to the side arm of a directional coupler. Two Bolovacs can be employed to calibrate the directivity and coupling factor of directional couplers. In either case, the Bolovac serves as a standard of rf power, while conventional meters or detectors need rf calibration.

One may reasonably expect additional applications of the Bolovac either as a voltmeter or as a source of known voltages, a standard of current, or a powerabsorption mount when it is commercially produced and receives wide laboratory use.

\section{Structural Features of the Bolovac}

\subsection{Mechanical Design}

First generation Bolovacs at the National Bureau of Standards are illustrated in some detail in reference [3]. Some figures stressing salient features are reproduced for the reader's convenience. Major up-todate modifications are also pointed out.

Figure 1 illustrates conceptually the bolometer assembly in the center plate of the Bolovac. The first National Bureau of Standards bolometers had solid substrates clamped, soldered or cemented to the center plate. This is also shown schematically in figure 15 and figure 16 shows the physical location of the bolometer in the split center plate. More recent units (fig. 17) used 2-mil-thick plastic substrates.

To date the general approach in the National Bureau of Standards design uses three plates plus the bolometer to form a core that fits into a nest of a large three-ring assembly adding more capacity, $C_{b}$, to the outer conductors of the core (figs. 18 and 19). The assembly in figure 19 allows the Bolovac to operate down to about $0.5 \mathrm{MHz}$. As was partly discussed in the principle of operation, the core alone operates in a range from about 0.1 to $1 \mathrm{GHz}$ and the metal output plate of this core is replaced by a bakelite or plastic one for frequencies above $1 \mathrm{GHz}$. Two or more capacitive rings can be used that fit into each other successively depending on application goals. The values of $C_{b}$ and the residual series and shunt inductances that 
affect the resonant frequencies of these radial transmission lines [4] also can be varied by controlling the thickness of the dielectric and the number and size of metallic bolts that hold the assembly together.

A version of an interchangeable bolometer (fig. 20) constructed as a separate unit and employing a 2-mil

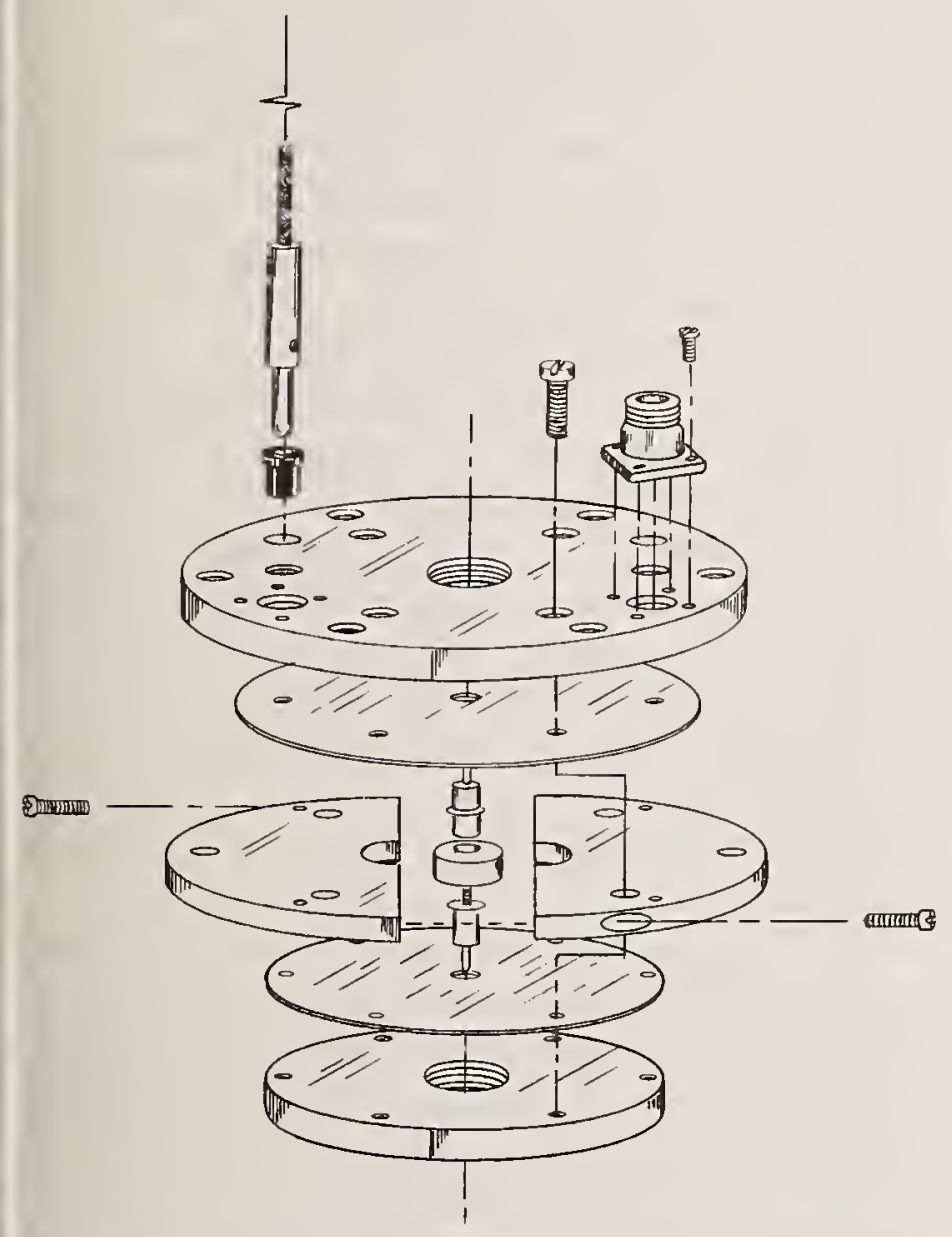

FIGURE 15. Exploded view of core for voltage standardization.

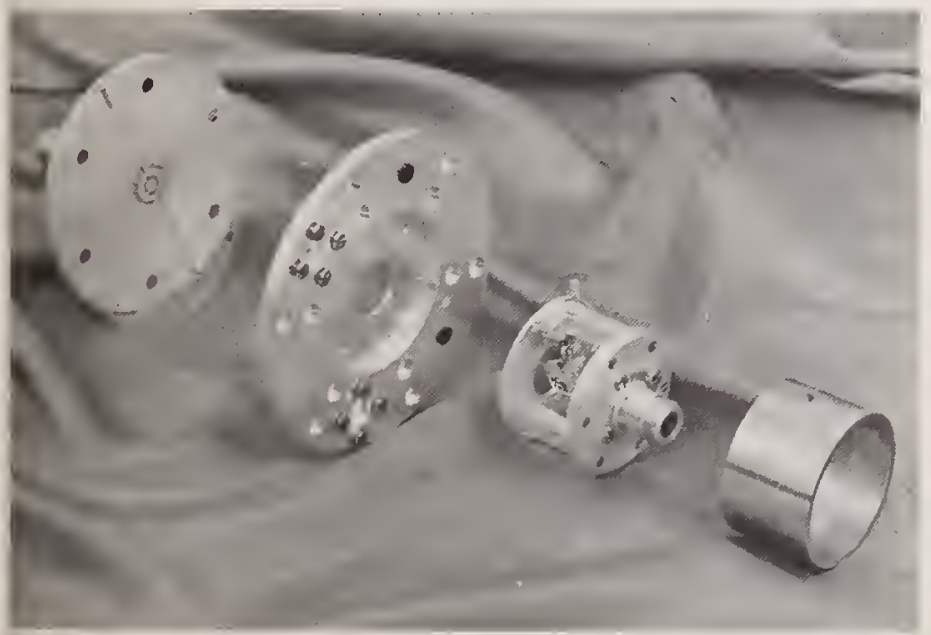

Figure 16. Current core exploded. substrate is one of a number of possible variations in the Bolovac design. This interchangeable element is referred to as a "bolometer cell". The only thing common to the rings and core is that the center plate in all of them is split along the diameter. Figure 21 shows the application of the Bolovac to calibrate a voltage standard (ATVM).

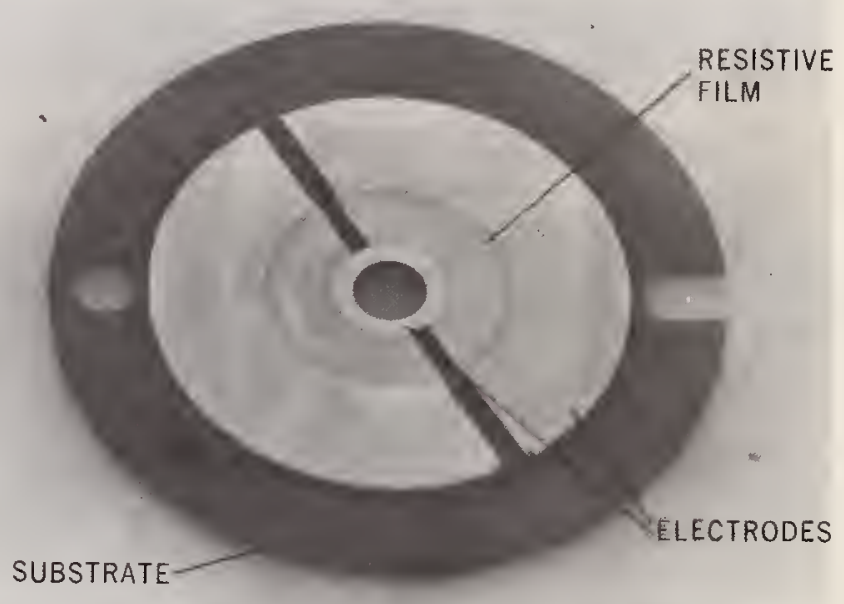

Figure 17. Bolometric film on two-mil plastic substrate.

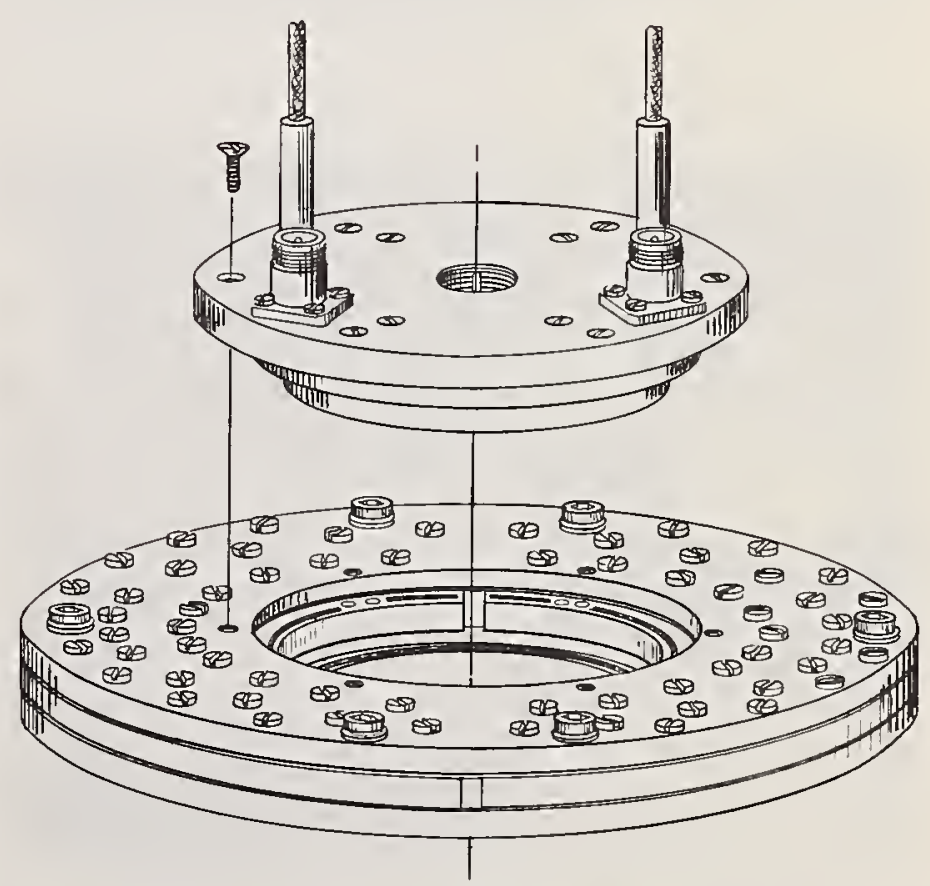

FIGURE 18. Core (with voltage plate) and auxiliary capacitor of Bolovac. 


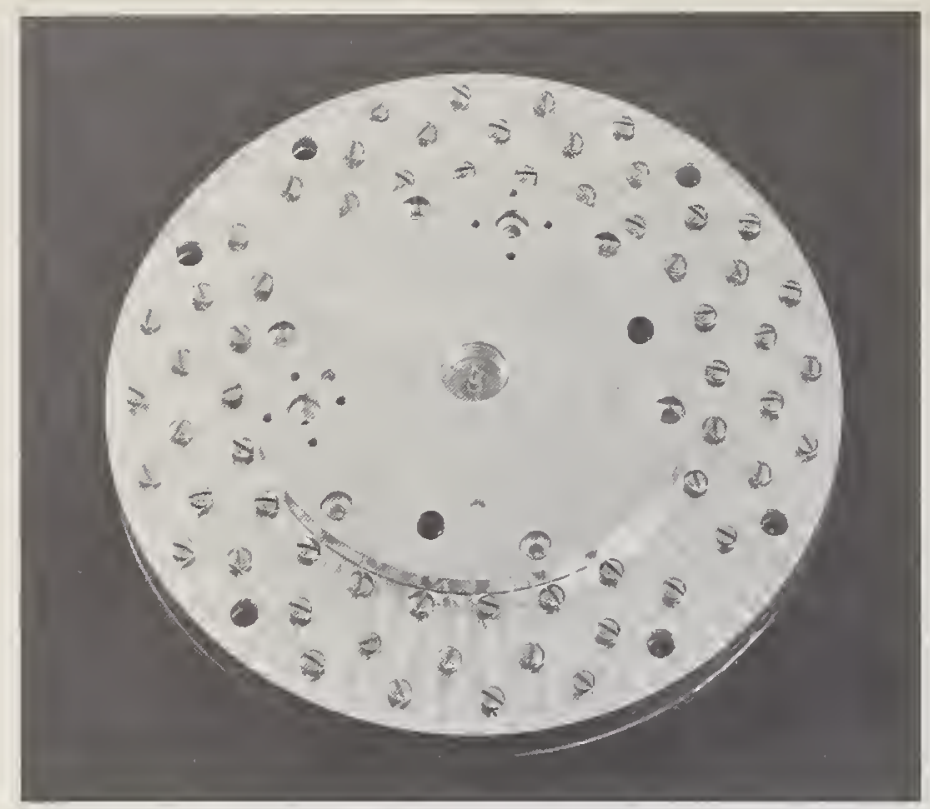

Figure 19. Voltage core and auxiliary capacitor.

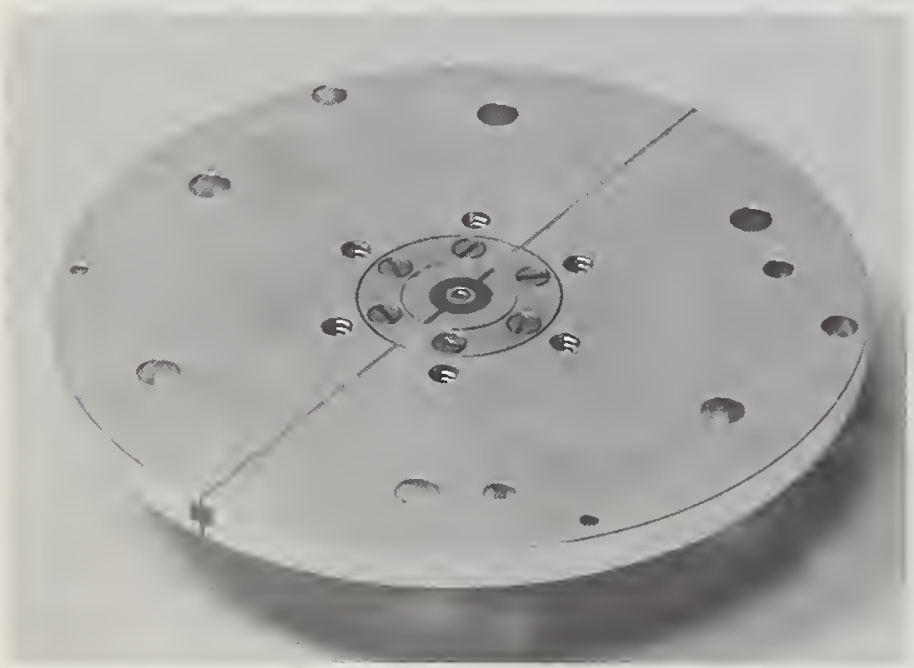

FIGURE 20. Interchangeable bolometer cell (employing a 2-mil substrate) mounted in the center plate of the Bolovac.

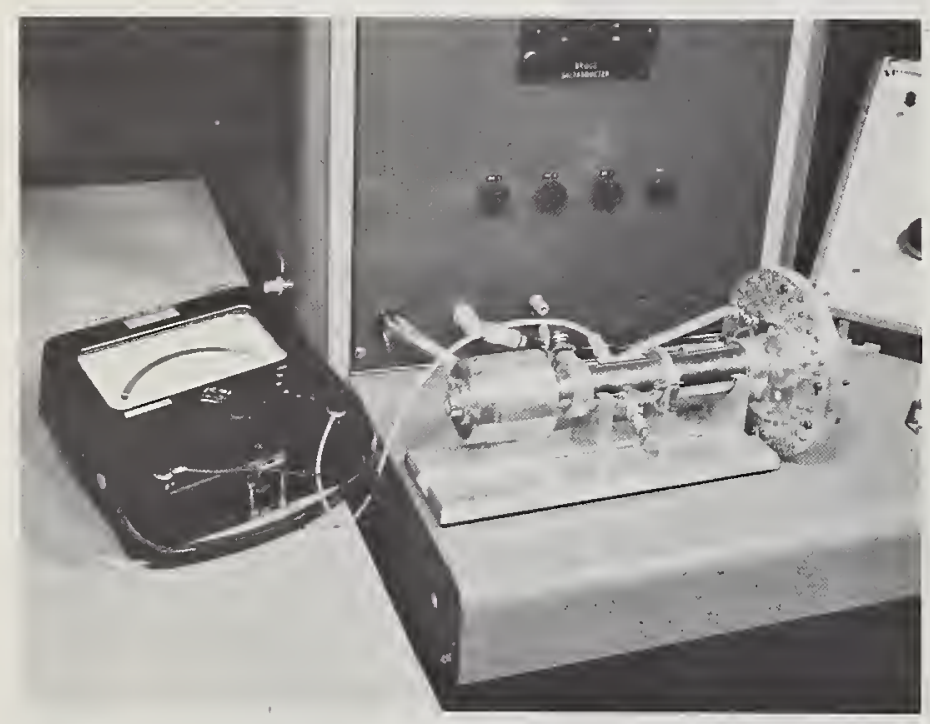

Figure 21. Bolovac set up to calibrate attenuatorthermoelement voltmeter ( $A T V M)$.

\subsection{Thin-film Materials for the Bolovac}

Details on fabricating bolometers for the Bolovac are a subject for a separate paper to be published by the National Bureau of Standards or by another laboratory choosing to abandon proprietary rights, if any. The remarks to follow are based on up-to-date experience at the National Bureau of Standards, on a cursory search of some of the vast amount of published literature on thin films, on direct contact by the author with experts outside the National Bureau of Standards and with private concerns, and on the opinions and recommendations of Paul E. Werner who was solely responsible for the film deposition for these bolometers at the National Bureau of Standards. The reader is referred to the recent books and surveys on the subject and to exhaustive references to hundreds of papers in these issues [15-27].

The most important characteristics of the bolometer are the sheet resistivity, $R_{s}$, measured in ohms per square, the stability of $R_{s}$, and its temperature coefficient of resistance (TCR) in percent per degree $C$ of the film. Others are mechanical stability, power dissipation, reliability of electrical contacts to the conductors of its mount, and low residual noise. Only the first two, $R_{s}$ and TCR will be discussed. A basic requirement, as stated earlier, is that the rf resistance equal the dc resistance of the unit at all frequencies in question.

Based on free-space characteristic wave impedance, $R_{s}$ should be $377 \Omega / \mathrm{sq}$ for any air-dielectric transmission system having two or more conductors [28]. The TCR should be as high as possible. One must keep in mind that the minimum acceptable TCR value depends entirely on the signal-to-noise ratio $(\mathrm{S} / \mathrm{N})$ of the bridge and Bolovac setup and of the desired dynamic range. The only objective of the TCR is to enable the bridge galvanometer to tell us when the original value of $R_{s}$ is restored. At the National $\mathrm{Bu}$ reau of Standards, using good quality commercial bridge components, platinum and nickel films on $3 / 32^{-}$ to $1 / 8$-inch solid glass or on 2-mil plastic substrates are satisfactory for low $R_{B}$ bolometers. The resulting sensitivity, $\gamma$, expressed as the change of bolometer resistance in ohms per watt was in the range of 1 to 10. The corresponding TCR of the film materials was in the range of 0.1 to $1.0 \mathrm{percent} / \mathrm{deg}$. C. One should be able to improve the $\mathrm{S} / \mathrm{N}$ ratio and employ film materials having TCR values of 0.01 to 0.1 particularly if willing to sacrifice some dynamic range. Correlation between the dynamic range of the setup, its sensitivity and resulting accuracy is given in reference [29]. 
No serious film-deposition problems were encountered at the National Bureau of Standards for $R_{s}$ values up to $10-\mathrm{ohms}$. One of the first $25-\Omega$ platinum bolometers fabricated on a glass substrate remained in stable operation for over two years and failed because of a lose center-pin assembly. However, other such $25-\Omega$ disks were not reproduced. As said before, $50-\Omega$ evaporated carbon-film bolometers on 2 -mil plastic substrates lasted long enough for us to establish $\mathrm{rf}$-dc resistance equation to $18 \mathrm{GHz}$; additional repeated verifications are needed. Some very limited laboratory work is in progress at the National Bureau of Standards to improve the bolometer assembly and to select the best film materials for high $R_{s}$ values.

In scanning the thin-film literature one seems to find little quantitative information on high $R_{s}-$ high TCR materials and on film characteristics at frequencies through microwaves. Films are generally subdivided into "thin" and "ultrathin" [30]. Thin metallic films seem to imply thicknesses at which their electrical characteristics approach those of the corresponding bulk material. Their resistivities are about 45 percent higher and their TCR is 30 to 60 percent lower than the bulk [31,32]. Ultrathin films refer to smaller thicknesses starting with the "critical" thickness, $d_{o}$, at which $d c$ conductivity begins. The thin alkali-metal continuous films generally have thicknesses exceeding 3 to 4 atomic layers [33], while ultrathin films consist of "islands" of the material coming in contact with each other at the thickness of $d_{o}$. Unfortunately there is a wide disagreement on the numerical values of these thicknesses. For example, thin copper films are quoted in one case as starting at $300 \AA^{3}$ and in another at $3800 \AA$ [34]. Since the TCR is a function of the film thickness, as well as of other conditions, its value seems equally uncertain. Ultrathin films generally refer to thicknesses below $100 \AA$ [35]; their resistances may or may not remain constant with time, depending on many parameters of the material and conditions under which they were produced. Among these factors are the characteristics of the film material itself, the characteristics and temperature of the substrate materials and the conditions of its surface, the rate of the film disposition, the deposition vacuum, the presence of impurities in the deposited material, the presence of and kind of residual gas in the vacuum chambers, and the aging of the film. The mean free path $(\mathrm{mfp})$ of the conduction electrons in the film and the scattering or reflections of some of these electrons by both the top and bottom surfaces of

\footnotetext{
${ }^{3} \mathrm{An}$ angström is a unit of length equal to $10^{-10}$ meters; its symbol is $\AA$.
}

the film may have an appreciable effect on the resulting resistivity of the film. A method widely used to determine the structure and characteristics of films is to measure the electrical impedances of various samples of known dimensions. One would therefore have to resort to an enormous amount of experimentation in addition to what has already been done to obtain the missing desired data on high $R_{s}=$ high TCR films. It seems more practical for our purpose to employ the trial-and-error approach when choosing the best combination of film and substrate materials and film-deposition conditions required for the specific bolometer $R_{B}$ values.

Another important justification for the above empirical approach is the advisability of checking the rf characteristics of each new bolometer type throughout its usable frequency range, even though $R_{s}$ has not been found to be frequency dependent at these frequencies in published literature. Considerable studies have been made on the so-called "anomalous skin effect" of metal films i.e., how frequency affects the surface impedance of these films. This effect results from the expected interdependence between the $\mathrm{mfp}$ of the electrons in the film and the depth of the current penetration into the film material at various frequencies. An analytical prediction [36] shows no appreciable departure from the classical behavior should be expected at frequencies below the infra-red at ordinary temperatures (above $0^{\circ} \mathrm{C}$ ) and that the anomalous skin effect is essentially a low-temperature phenomenon. The effect was observed for bismuth films at $23.5 \mathrm{GHz}$ at temperatures of $2^{\circ} \mathrm{K}$. [37, 38]. Thin and ultra-thin films having resistivities many times that of the bulk material may be tried to produce Bolovac disks as long as their resistances are stable and reproducible. The Bolovac is particularly suited for measuring $R_{s}$ values of various films at microwave frequencies in preference to resonant cavity or other methods. The physical shape of the samples is essentially the same as recommended for this purpose in the literature [39] and the fairly simple procedure for measuring $R_{s}$ described above in Section 3.2a. (2) can be applied. Direct comparisons of high and low $R_{s}$ values can be readily obtained. The Bolovac thus turns out to be a valuable and efficient tool for studying properties of materials.

Films having high $R_{s}$ value can be obtained by employing (1) ultrathin films of single metals, (2) thin refractory metals, (3) thin metallic alloys, (4) semiconductors and (5) cermets. Anisotropic metals, such as molybdenum, should be avoided. It is likely that a number of laboratories already have the desired 
materials and deposition techniques. Unfortunately and understandably the information is most likely of a proprietory nature. Some of the possible promising prospects of materials are indicated below [40].

Radial narrow-strip sensing elements (instead of half-disks) may be used for $R_{s}$ values of $50-\Omega$ employing platinum, nickel and other low-resistivity metals. This approach is practical only if one can eliminate the residual inductance of the diametrically placed strips; this is required to avoid a possible serious frequency effect on $R_{B}$. We had no opportunity to try this type of bolometer at the National Bureau of Standards, but it does have a wide application in commercial power mounts [41].

High $R_{s}$ and high negative TCR can also be fabricated with single metals [42]. Ultrathin single-metal films deposited on a plastic substrate have large positive TRC's when the thermal-expansion coefficient of the substrate is 10 times larger than that of typical metal [42]. It may be worth while to explore the frequency effect on such films.

Among the high-resistivity and refractory metals, bismuth, tungsten and zirconium can be considered. Bismuth has a $d_{o}$ of $35 \AA$ and a high resistivity and high negative TCR at a thickness of several hundred ångströms [43, 44]. Resistances of up to $500 \Omega / \mathrm{sq}$ with fair negative TCR's can be obtained with tungsten and other refractory metals [45].

Of the various alloys referred to in the literature chromium-nickel, $\mathrm{Cr}-\mathrm{Ni}(20: 80)$, is applicable for $R_{s}$ values of $400 \Omega / \mathrm{sq}$ and positive TCR's of 0.01 to 0.02 percent per degree $C$. Others are listed in the same reference [45].

As previously indicated, encouraging results were obtained at the National Bureau of Standards with evaporated carbon using an evaporation technique similar to the one described in $[46,47]$. Tin oxide having a sufficient TCR is another semiconductor material to be considered [47]. Semiconductor films, e.g., indium-antimonide, should be tried, though little work has been done to date on these materials [48].

Cermets are mixtures of a metal and a dielectric. Chromium and silicon oxide, $\mathrm{C}_{r}-\mathrm{S}_{i} \mathrm{O}$, are often mentioned for $R_{s}$ values up to $600 \Omega /$ sq with fair negative temperature coefficients [45]. These types of films seem to open up a wide range of prospects for the present needs [49]. Relatively high $R_{s}$ bolometric films fabricated outside the National Bureau of Standards are briefly referred to in the appendix.

\section{Auxiliary Equipment}

Designing direct-readout circuits for various applications of the Bolovac seems feasible, but is outside the scope of this paper. Therefore, the immediate applications above assume familiarity by the user with various components and rudimentary precautions required in making $\mathrm{rf}$ measurements at the frequencies in question. These components include bias-power substitution bridges, sources of $\mathrm{rf}$ and biasing power, high-impedance dc or audio voltmeters (DVM's), galvanometers, frequency meters, isolators, coaxial switches, etc. The quality and the inclusion of specific components into a measurement setup will affect the accuracy of the results. In all cases commercial equipment is adequate to realize the advantages indicated above in measuring power. Voltage- and currentmeasurement applications are a completely new extension into a range of frequencies where accurate measurements were not previously possible.

Power-substitution bridges of various kinds have been described extensively in published literature $[5$, $50,51]$. For high precision measurements the reader is referred to a recently developed National Bureau of Standards dc biasing bridge [52]. Because the Bolovac has a much wider dynamic range and range of $R_{s}$ values than typical present-day commercial mounts, the range of resistors, currents, voltages, and power of a bridge will have to be either broad enough to cover an entire class of Bolovacs (e.g., $R_{B}$ values of 0.1 to $50 \Omega$ ) or limited to a narrow range (e.g., 45 to $55 \Omega$ ).

\section{Conclusion and Future Prospects}

Bolovac applications open up new approaches to investigations that employ direct measurement of microwave voltages and currents. They introduce superior power-measurement methods based on more familiar concepts and procedures and yield higher accuracies than present test equipment provides.

The physical version of the National Bureau of Standards-constructed Bolovac can be reproduced and used with solid- or flexible-substrate bolometers. Bolometers having $R_{B}$ values of $10 \Omega$ (surface resistivities of about $80 \Omega / \mathrm{sq}$ ) or lower, using platinum or nickel films were used succesfully at the National Bureau of Standards. Carbon films show good promise for higher $R_{B}$ values but were not yet tried on solid substrates. Searching the up-to-date literature on thinfilm deposition indicates promising prospects for highresistance metals and other materials for high- $R_{B}$ bolometers. 
One can logically expect further improvements and industrial refinements on any first-generation devices as they are placed on the market. However, manufacturing the Bolovac affords selections of a very wide range in structural features far exceeding relatively simple modifications. A manufacturer can readily exploit these as proprietory-right elements. For example, there is a wide range of thin-film materials and structural details that secure high stability and sensitivity of the bolometer plus a wide range of frequencies and dynamic ranges to choose from. The sensitivity and accuracy of the Bolovac and associated bridge offers another aspect to be considered. Size and weight of the Bolovac, size of the transmission lines, type of connectors, including a universal design to accommodate many types of connectors (e.g., type N, LPC, etc.) for a given system, ease of assembly and modifyling the Bolovac to add or remove capacity rings, design to eliminate capacity rings, all are factors in choosing a specific design. The economic aspect, life expectancy and reliability are most important in this respect as with any product on a competitive market. Readout-circuit development of incorporating the Bolovac in automated systems of measurement are two other areas that offer room for individual imagination and initiative; these seem particularly challenging for wide-band calibration and evaluation of power meters, signal generators, sources of rf, pulsedisplay oscilloscopes, spectrum analyzers and the like.

An entirely different type device closely similar to the Bolovac and nearly identical to its application is the "Thermovac" [1]. Employing a thermoelectric detector in place of the bolometer it may prove attractive for marketing primarily because of two features. (1) The bridge required for the Bolovac is replaced with a dc or af voltage output reading instrument. (2) It may be more economical to fabricate high- $R_{B}$ value thermoelectric disks; a certain type of such disks has in fact been used recently with commercial power meters [53]. Thus, the prospects for variability in marketing and application of the Bolovac and its equivalents seem almost limitless.

Appreciation is hereby expressed to P. E. Werner for the numerous discussions we had with him and for his review of the section on thin films; also to A. R. Ondrejka and R. A. Lawton for their careful review of the manuscript.

\section{References}

[1] Selby, M. C., Electrothermic instruments for measuring voltage and current, U.S. Patent 3487305 (Dec. 1969).

[2] Selby, M. C., Voltage measurement at high and microwave frequencies in coaxial systems, Proc. IEEE 55, No. 6, 877-882 (June 1967).

[3] Selby, M. C., Bolovac application for H.F. and microwave power measurement and standardization, J. Res. Nat. Bur. Stand. (U.S.), 74C (Eng. and Instr.), Nos. 3 and 4, 123-133 (July-Dec. 1970).

[4] Selby, M. C., The Bolovac and its applications, IEEE Trans. Instr. Meas. IM-19, No. 4, 324-331 (Nov. 1970).

[5] Selby, M. C., Bolometric voltage and current (BOLOVAC) standard for high and microwave frequencies, J. Res. Nat. Bur Stand. (U.S.), 72C (Eng. and Instr.), No. 1, 61-79 (Jan.-March 1968).

[6] Ragan, G. L., Microwave Transmission Circuits, MIT Rad. Lab. Series 9, pp. 105-106, McGraw-Hill Book Co., Inc., New York, N.Y., (1948).

[7] Ramo, S., and Whimery, J. R., Field and Waves in Modern Radio, 2d ed., 395-401 (John Wiley \& Sons, Inc., New York, N.Y., 1953).

[8] DeLoach, B. C., Jr., Radial-line coaxial filters in the microwave range, IEEE Trans. MTT 11, 50-55 (Jan. 1963).

[9] Varon, D., Radial-line band rejection filters in coaxial waveguides, IEEE Trans, MTT 15, 680-687 (Dec. 1967).

[10] Selby, M. C., Single-bolometer series-parallel circuit for accurate voltage and power measurement, Proc. 19th Annual ISA Conf. \& Exhibit, New York, N.Y., Oct. 1215, 1964, pp. 21.6.1.64-1 to 21.6.164-12 (Oct. 1964).

[11] Sucher and Fox (editors), Handbook of Microwave Measurements, 3d ed., Vol. 1, p. 186ff (Polytechnic Press, Polytechnic Institute of Brooklyn, Brooklyn, N.Y., 1963).

[12] Ginzton, E. L., Microwave Measurements (McGraw-Hill Book Co., Inc., New York, N.Y., 1947).

[13] Microwave power measurements, Hewlett-Packard Company, Appl. Note 64, October 1965.

[14] Selby, M. C., Accurate radio-frequency microvoltages, Trans. AIEE 72 (Commun. and Elect.), Paper 52-33, 158-163 (May 1953).

[15] Chopra, K. L., Thin film phenomena (McGraw-Hill Book Co., Inc., New York, N.Y., 1969).

[16] Maissel, L. I., and Glang, R., Handbook of thin film technology (McGraw.Hill Book Co., Inc., New York, N.Y., 1970)

[17] Dummer, G. W. A., Materials for Conductive and Resistive Functions (Hayden Book Company, New York, N.Y., 1970).

[18] Espe, Werner, Materials of High Vacuum Technology (Pergamon Press, Elmsford, N.Y., 1966)

[19] Keonjian, Edward, Microelectronics, pp. 181-191, 256257 (McGraw-Hill Book Co., Inc., 1963).

[20] Halaby, S. A., Gregor, L. V., and Ruben, S. M., The materials of thin-film devices, Electro-Technology, No. 57, 95-122d (Sept. 1963).

[21] Hass, Georg, and Thun, R. F., Physies of Thin Films, 3, (Academic Press, New York, N.Y., 1966).

[22] Powell, C. F., Oxley, J. H., and Blocher, J. M., Jr., Vapor Deposition (John Wiley \& Sons, Inc., New York, 1966).

[23] Dushman, Saul, Scientific Foundations of Vacuum Technique (John Wiley \& Sons, Inc., New York, N.Y., 1949).

[24] Holland, L., Vacuum Deposition of Thin Films (John Wiley \& Sons, Inc., 1956).

[25] Hughes Electronic Properties Information Center [EPIC], Interim Reports No. IR-26 and IR-47.

[26] Ault, C. M., Triller, D. P., Curry, R. W., and Hague J. D., U. S. Naval Avionic Facility, Fabrication and Evaluation of Vacuum Deposited Cermet $\left(\mathrm{C}_{\mathrm{r}}-\mathrm{S}_{\mathrm{i}} \mathrm{O}\right)$ Resistors, Technical Report TR-688, Indianapolis, Indiana 46218, (Jan. 1966).

[27] Belser, R. B. and Micklin, W. H., Electrical Conductivity Studies of Metallic Films. WADC Technical Report 57-660. ASTIA Document No. AD 1555573 (Dec. 1957). 
[28] Moreno, Theodore, Microwave transmission design data, p. 33 ff (Dover Publications, New York, N.Y., 1958).

[29] Selby, M. C., Single-bolometer series-parallel circuit for accurate voltage and power measurement. Op. cit, figure 4.

[30] Neugebouer, C. A., Electrical resistivity of ultrathin metallic films, Trans. 9th Nat'l. Vacuum Symposium, p. 45 (The Macmillan Company, New York, N.Y., 1962).

[31] Belser, R. B. and Hicklin, W. H., Temperature coefficients of resistance of metallic films in the temperature range of $25^{\circ}$ to $600^{\circ} \mathrm{C}$, J. Applied Phys. 30, No. 3, 313-322 (March 1959).

[32] Komnik, Yu F., and Palatnik, L. S., The influence of the structure of thin films on their electrical conductivity, Soviet Physics-Solid State 7, No. 2, 429-431 (August 1965).

[33] Maissel, op. cit., p. 13-11.

[34] Chopra, op. cit., p. 189.

[35] Ibid, p. 85.

[36] Reuter, G. E. H., and Sondheimer, E. H., The theory of the anomalous skin effect in metals, Proc. Royal Society (London) A195, 336-364 (1948).

[37] Chopra, op. cit., p. 409.

[38] Rohderick, E. H., Electrical properties of thin-films, British J. Appl. Phys. 15, 617 (1964).

[39] Maissel, op. cit., p. 13-26.

[40] Ibid, chapters 13 and 18.

[41] Sakurai, K., and Nemoto, T., A thin-film bolometer unit, IEEE Trans. Instr. Meas. IM-16, No. 3, 206 (Sept. 1967).
[42] Neugebower, op. cit.

[43] Duggal, V. P., Rup, Raj., and Tripathi, P., Quantum size effect in thin bismuth films, Appl. Phys. Letters 9, No. 8, 293 (Oct. 15, 1966).

[44] Komnik, op. cit.

[45] Chopra, op. cit., p. 388, table III.

[46] Holland, op. cit., p. 398 .

[47] Maissel, op. cit., p. 18-22, 18-23.

[48] Chopra, op. cit., Chapter VII, p. 434.

[49] Gregor, op. cit., p. 103, Fig. III-7.

[50] Wind, M., Handbook of Electronic Measurements, I, 358ff, (1958).

[51] Sucher and Fox. op. cit., p. 190ff.

[52] Larsen, N. T., and Clague, S. R., The NBS type II power measurement system, ISA 25th Annual Conf. Proc., paper 712-70, (Oct. 26-29, 1970).

[53] Hopfer, S., Riederman, N. H., and Nadler, L. A., The properties of thermoelectric elements as microwave power detectors, 1962 IRE International Convention Record, Part 3, 77-84, (1962).

[54] Lane, J. A., Transverse film bolometers for the measurement of power in rectangular waveguides, IEE 105B, paper No. 2488R, 77-80 (January 1958).

[55] Lemco, I., and Rogal, B., Resistive film milli-wattmeters for the frequency bands 8.2-12.4 GHz, and 26.5-40 GHz, Proc. IEE, Pt. B, 427-430 (Sept. 1960).

[56] Schiffman, B. M., Young, L., and Larrick, R. B., Thinfilm waveguide bolometers for multimode power measurement, IEEE Trans. G-MTT 12, No. 2, 155-163 (March 1964).

\section{Appendix}

Lane [54] used thin-film elements in rectangular waveguides for measuring power at $10 \mathrm{GHz}$. Sheet resistivities of $220 \Omega$ /sq were deposited by sputtering platinum on $10^{-2}-\mathrm{cm}$ mica substrate at a pressure of the order of $10^{-2} \mathrm{~mm} \mathrm{Hg}$. The resistance was adjusted by heating the film on a hot plate. Gold electrodes were used. The continuous safe-power-dissipation rating was $100 \mathrm{~mW}$ and no change in the film resistance was noticed during his 2-month period of observation. He found the rf-dc power substitution held to within better than 3 percent and got an agreement of 1 percent with other methods. He concluded that these elements should be equally reliable for both $\mathrm{CW}$ and pulsed power in rectangular waveguides at any frequency.

Lemco and Rogal [55] used carbon films deposited on 5-mil bakelite and Nichrome evaporated on 4-mil crown glass having the same sheet resistivities as Lane. Their limits of uncertainty in measuring power was 2 percent at 8 to $12 \mathrm{GHz}$ for an instrument produced for the market. They also designed models for 12 to 18 and 26 to $40 \mathrm{GHz}$ and indicate promising results at these frequencies as well. They investigated sputtering platinum on mica but failed to reproduce resistances with this process.

Schiffman, Young and Larrick [56] used gold, silver, gold-germanium mixture, Nichrome or lead tellurium on thin sheets of mica or 2-mil thick corning glass for bolometers of sheet resistivities up to 400 $\Omega /$ sq. They expressed confidence in the stability of platinum films on mica and felt that these bolometers, employing rf-dc substitution measure power accurately up to frequencies for which the film thickness is less than the skin depth. 
U.S. DEPT. OF COMM.

BIBLIOGRAPHIC DATA SHEET

1. PUBLICATION OR REPORT NO.

NBS MN -123

4. TITLE AND SUBTITLE

BOLOVAC Systems for Measuring Electrical Quantities from

$0.5 \mathrm{MHz}$ Through Microwaves

\begin{tabular}{l|l} 
- Gov't Accession & 3. Recipient's Accession No.
\end{tabular} No.

5. Publication Date

January 1972

6. Performing Organizarion Code

7. AUTHOR(S)

Myron C. Selby

9. PERFORMING ORGANIZATION NAME AND ADDRESS

NATIONAL BUREAU OF STANDARDS, Boulder Labs

DEPAR TMENT OF COMMERCE

Boulder, Colorado 80302

12. Sponsoring Organization Name and Address

Same as No. 9

8. Performing Organization

10. Project/Task/Work Unit No.

11. Contract/Grant No.

13. Type of Report \& Period Covered

Final

14. Sponsoring Agency Code

15. SUPPLEMENTARY NOTES

16. ABSTRACT ( A 200-word or less factual summary of most significant information. If document includes a significant bibliography or literature survey, mention it here.)

A novel device - the BOLOVAC - is employed in measurement systems that furnish known voltages and currents up to $18 \mathrm{GHz}$, remove serious difficulties in power measurements, and are applicable in impedance, attenuation and other measurements. Typical of such measurements are the evaluation of rf power sources; calibration of power meters; measurement of net and incident power flow in a system; calibration of signal generators, voltmeters, current meters, picosecond-rise-time pulse-display oscilloscopes, spectrum analyzers; determination of insertion loss of components; and calibration of directional couplers. The Bolovac also serves as an accurately known resistive termination for match or mismatch applications from LF through microwaves.

Key words: BOLOVAC; calibration of current meters through microwaves; calibration of power meters through microwaves; calibration of voltmeters through microwaves; current measurement; disk-type bolometer evaluation; frequency-domain pulse evaluation; measurement of microwave current; measurement of microwave power; measurement of microwave voltage; mismatch error; picosecond rise-time pulse evaluation; power measurement; pulse-rise-time standardization; sampling oscilloscope standardization; spectrum analyzer standardization; termination mismatch error elimination; thin-film bolometers; voltage measurement.

\section{KEY WORDS (Alphabetical order, separated by semicolons)}

See above

\section{AVAILA BILITY STATEMENT}

X UNLIMITED.

FOR OFFICIAL DISTRIBUTION. DO NOT RELEASE TO NTIS.

\begin{tabular}{|l|c|}
$\begin{array}{l}\text { 19. SECURITY CLASS } \\
\text { (THIS REPORT) } \\
\text { UNCLASSIIED }\end{array}$ & 21. NO. OF PAGES \\
\hline 20. & 22. Price \\
UNCLASSIFIED & 30 cents \\
\hline
\end{tabular}


U.S. DEPARTMENT OF COMMERCE

National Bureau of Standards
Washington, D.C. 20234

OFFICIAL BUSINESS

POSTAGE AND FEES PAID

U.S. DEPARTMENT OF COMMERCE

Penalty for Private Use, $\$ 300$

U.S.MAIL 